Article

\title{
A New Online Service for the Validation of Multi-GNSS Orbits Using SLR
}

\author{
Radosław Zajdel * (1), Krzysztof Sośnica (1) and Grzegorz Bury \\ Institute of Geodesy and Geoinformatics, Wroclaw University of Environmental and Life Sciences, \\ Wrocław 50-357, Poland; krzysztof.sosnica@igig.up.wroc.pl (K.S.); grzegorz.bury@igig.up.wroc.pl (G.B.) \\ * Correspondence: radoslaw.zajdel@igig.up.wroc.pl; Tel.: +48 713205617
}

Received: 30 August 2017; Accepted: 11 October 2017; Published: 14 October 2017

\begin{abstract}
In the last decade, we have been witnessing a rapid development of the constellations of Global and Regional Navigation Satellite Systems (GNSS/RNSS). Besides the well-known GPS and GLONASS, newly developed systems such as Galileo, BeiDou, QZSS and NAVIC have become increasingly important. All satellites of new GNSS are equipped with laser retroreflector arrays (LRA) dedicated to Satellite Laser Ranging (SLR). SLR allows, e.g., an independent validation of microwave-based orbit products. Therefore, a fully operational online service called the multi-GNSS Orbit Validation Visualizer Using SLR (GOVUS) has been developed allowing for near real-time analysis of the quality of multi-GNSS orbits. The mean offsets of SLR residuals for Center for Orbit Determination in Europe (CODE) orbits in 2016 are at the level of $-8,-38,-14$, and $-107 \mathrm{~mm}$, for BeiDou, Galileo, GLONASS, and QZSS, respectively, with the standard deviations of 66, 36, 29, and $100 \mathrm{~mm}$. Moreover, GOVUS can be used as a database containing information on equipment used at SLR stations and multi-GNSS satellite parameters. This paper includes a comprehensive description of the functionality and the structure of the developed service with exemplary analyses. The paper points out the most critical issues, limitations and challenges of multi-GNSS and SLR tracking network in the context of the SLR orbit validation. The goal of the paper and GOVUS itself is to determine: (1) what is the current quality of multi-GNSS orbits validated using SLR results; (2) what kinds of systematic errors can affect GNSS orbits and SLR observations; and (3) how to provide the online analysis tools to the broadest possible multi-GNSS community. The service has been officially operating since March 2017 as the Associate Analysis Center of the International Laser Ranging Service (ILRS ACC).
\end{abstract}

Keywords: SLR; multi-GNSS; orbit quality; ILRS AAC

\section{Introduction}

The multi-GNSS Pilot Project (MGEX) [1] was initiated in 2013 with the major motivation to increase the effort to prepare full integration of new constellations, e.g. Galileo, BeiDou, and QZSS, into the International GNSS Service (IGS) [2] processing routine, which is currently focused on GPS and GLONASS only solutions. Several IGS Analysis Centers (AC) prepare separately combined multi-GNSS solutions consisting of homogeneous and aggregated processing of all systems, i.e., GPS, GLONASS, Galileo, BeiDou, and QZSS. Processing of GNSS data for all mentioned navigational systems is complicated due to several satellite structural aspects, such as differences in signals and frequencies of transmitted data, shape, dimensions, and surface properties of satellites' bus and solar panels, and used technologies, for example, different attitude modes. On the other hand, the multi-GNSS orbit products are used by civil users, who expect intuitive and real-time information about the quality of multi-GNSS products. Therefore, it is possible to use the Satellite Laser Ranging (SLR) [3] technique as an independent validation tool for the orbit products. The approach of SLR 
validation of microwave-based GNSS orbits is well known and applied by many ACs [4-6]. However, there is a limited number of dedicated tools that would guarantee a constant and near real-time information about the quality of the products provided by particular ACs based on an autonomous SLR validation process. Thus, a new Associated Analysis Center of the International Laser Ranging Service [7] at the Wroclaw University of Environmental and Life Sciences (IGG ILRS AAC) has been established providing a service called as multi-GNSS Orbit Validation Using SLR (GOVUS) as its main component.

\subsection{Ranging the GNSS Constellation}

Satellite Laser Ranging (SLR) is a technique of space geodesy for a direct monitoring of the objects in the Earth's orbit. Since 1964, the increase of both the precision of observations [3,8-10] and the development of advanced mathematical models reducing the impact of the systematic errors, e.g., troposphere delay modeling for optical wavelengths [11,12] could be observed. Nowadays, the SLR technique has assumed a leading position in space and satellite observation techniques among Very Long Baseline Interferometry (VLBI), Doppler Orbitography and Radiopositioning Integrated by Satellite (DORIS) and Global Navigation Satellite Systems (GNSS). The SLR measurements performed to the geodetic satellites (LAGEOS 1 and 2, LARES, Etalon, Stella, etc.) provide geodetic parameters for the International Terrestrial Reference Systems (ITRS) realizations: (1) the origin of the geocentric reference frame; and (2) the global scale [13,14]. Moreover, SLR delivers values of the standard gravitational parameter, GM, and low-degree spherical harmonics of the Earth's gravity field [15-17]. On the other hand, nearly all GNSS satellites are equipped with the onboard Laser Retroreflector Arrays (LRAs). The scheduled modernization of GPS spacecraft to the Block-III will begin in 2018 and provide satellites with full SLR tracking support [18]. In the near future, there will be more than 100 GNSS satellites with the capability of SLR tracking [19]. Ranging the GNSS constellation using SLR could strengthen the combined precise orbit determination $[20,21]$ or even allow the orbit determination using solely SLR data [22,23], validate new radiation pressure models [24-28] and enhance the co-location of techniques employing the co-location in space onboard GNSS spacecraft $[29,30]$. SLR is also essential in providing information about clock behavior in space [31,32].

However, the co-location in space requires an advanced analysis of all systematic errors which may limit the consistency level between GNSS and SLR techniques [30,33]. These errors include: the satellite signature effect, i.e., the effect related to laser reflections from multiple corner cubes; range and time biases in SLR; differences between nighttime and daytime SLR observations due to using optical filters; variable position of satellite center-of-mass and errors in the laser retroreflector array optical centers; microwave antenna phase center offsets and their variations; and errors in modeling satellite attitude and orbits. Moreover, errors in the modeling of optical and microwave signal propagation in the atmosphere, such as higher order ionosphere delay corrections with signal bending for GNSS and currently neglected horizontal gradients of troposphere delay in SLR processing, may also limit the consistency level between SLR and GNSS [34]. The aim of GOVUS is to identify possible issues, such as range biases, orbit errors, signature effects, and wrong antenna offsets, all of which limit the consistency between SLR and GNSS, and introduce discrepancies between both space geodetic techniques. All of these issues must be first identified and then modeled or eliminated to provide a co-location in space free of systematic errors.

The main merit of the SLR technique is the very high potential of the measurement accuracy as the result of beneficial propagation of a light pulse in the Earth's atmosphere [3,11,29]. The visible and infrared electromagnetic waves are almost insensitive to the water vapor, which is one of the main components of the Earth's troposphere and the source of the microwave delay in GNSS, VLBI or DORIS techniques. Consequently, the tropospheric delay is well modeled for SLR observations and additionally the ionospheric impact on laser beam is practically negligible [35]. These result in an accuracy of the range measurement at the millimeter level. However, the accuracy of the dataset is dependent on the station-satellite pair, especially in the case of different, large and flat LRA, which 
are used onboard the GNSS satellites. The characteristics of the equipment used at stations may impose systematic biases in reference to particular GNSS satellites, such as the Satellite Signature Effect (see Section 3.1).

\subsection{Role of GOVUS in the Development of SLR and Multi-GNSS}

There are three main potential users of GOVUS: (1) ILRS stations and users of their products; (2) MGEX ACs; and (3) users of multi-GNSS products. The existing ACs and Associated Analysis Centers (AAC) of the ILRS are mostly focused on the processing of the measurements to the geodetic satellites (e.g., LAGEOS, Etalon, and LARES). In 2016, the number of Normal Points to High Orbiting Objects was already larger than the number of Normal Points to the LAGEOS satellites by about $5 \%$. Therefore, the SLR observations to GNSS may have a great potential for the geodetic community in terms of providing a link between SLR and GNSS and for deriving global geodetic parameters. The GOVUS service is one of a few ILRS ACs focused on making use of SLR observations to GNSS satellites. The tools available in GOVUS give both the stations and the users detailed information about the daily performance of the whole network, as well as particular stations.

The GNSS satellite constellation is the most emerging group of SLR targets in the last decades, hence the laser stations will be soon struggling with progressively more difficulties in monitoring many overlapping passes [36]. The laser stations have been intensively working on the optimization of tracking schedules for GNSS, with a care not to suffer the primary LAGEOS tracking at the same time. The most technologically advanced stations, e.g., Herstmonceux in the UK, allow for a daytime tracking and efficient switching between satellites, which improves the tracking schedule and essentially increases the data yield without impacting on the priority of LAGEOS and LEO satellites tracking [23,36]. The consciousness of the performance of the laser stations is essential in a proper evaluation of the MGEX products. Currently used, publicly available information about the SLR validation of the multi-GNSS products is officially delivered by the MGEX in the form of static plots and tables [37]. The goal of GOVUS is to extend the information delivered by current services with the functionality of the up-to-date public database supported by user-friendly, interactive tools. The goal of GOVUS is also to allow for more complex investigations through filtering of source dataset, e.g., to exclude unreliable laser stations, blunders, or to focus on the particular aspects of the observational frame in the context of relative positions of the satellite with respect to the position of the Earth and the Sun. With this functionality we are able to divide the biases which actually originate from the stations' characteristics, e.g., range biases, detector-related biases, from general problems of models used for the multi-GNSS orbit determination, e.g., mismodeling of the solar radiation pressure, antenna thrust, albedo or mismodeling of the satellite attitude, as well as an anomalistic behavior of particular satellites in the constellation. All of these capabilities would crosslink the extensive knowledge about the station-satellite dependencies and multi-GNSS orbit quality. Both IGS and ILRS provide today observations originating from the multi-GNSS constellation and put a lot of effort on a continuous and comprehensive improvement of multi-GNSS products. Therefore, data and tools available for every user in GOVUS may contribute to strengthening the link between IGS and ILRS communities as their common interest is using GNSS products of the highest possible quality.

\subsection{The Objective and Structure of This Paper}

This paper describes the functionality and methodology of computations offered by IGG ILRS AAC. The developed service called GOVUS is focused on generating scientific products based on the SLR observations to the GNSS satellites on the operational basis in the near real-time mode. Section 2 provides the core information about the components of the system with a description of the computational algorithms. Furthermore, it describes the possible range of use with regard to the needs and expectations for SLR tracking of GNSS built up by the scientific community, especially in the context of improving the MGEX products. Section 3 provides sample analyses performed using the publicly available dataset and tools delivered by GOVUS. The analyses concern mainly the assessment 
of overall multi-GNSS orbit quality. The conclusions and the overview of prospects for the multi-GNSS community resulting from GOVUS are drawn in the last section.

\section{Materials and Methods}

\subsection{System Overview and Description of Processing Flow}

The GOVUS system consists of two main components: (1) server-side algorithms, which execute the daily SLR validation process, prepare the dataset of SLR residuals and summary reports; and (2) web-application for visualization and analyses of SLR residuals. The system constitutes, therefore, a complex, autonomous, and fully automated tool. The web-application is a completely self-sufficient tool for conducting analyses, which do not require any additional software or drivers. All analyses can be done using solely the web browser.

The SLR residual is a difference between the distance derived directly from laser ranging and calculated between the fixed station coordinates and the microwave-based position of a satellite. SLR validation at the GNSS altitudes has the largest sensitivity in radial direction [38], because of the limited scope of possible incidence angles in laser ranging, generally up to $15^{\circ}$ (see Figure 1 ). The SLR validation is only possible when both orbit products and SLR normal points are available.

Processing of data is performed using the modified Bernese GNSS Software 5.2 [39]. Figure 2 shows the processing scheme of microwave orbit validation using SLR dataset in Bernese GNSS Software. Currently, only the CODE orbit products are being validated as a representative example of 5-system orbit products delivered in the framework of MGEX. CODE solutions include satellites of the following systems: GPS, GLONASS-M, GLONASS-K, Galileo IOV, Galileo FOC, BeiDou-2 MEO, BeiDou-2 IGSO and QZSS. Besides CODE, there are five other ACs which deliver multi-GNSS orbit products in the framework of MGEX: Centre National d'Études Spatiales (CNES/CLS) [4], Helmholtz Centre Potsdam German Research Centre for Geosciences (GFZ) [5], Technische Universität München (TUM), Wuhan University (WU) [40] and Japan Aerospace Exploration Agency (JAXA) [41]. Products from all ACs can be included in the GOVUS service, which is one of the major plans for the future development.

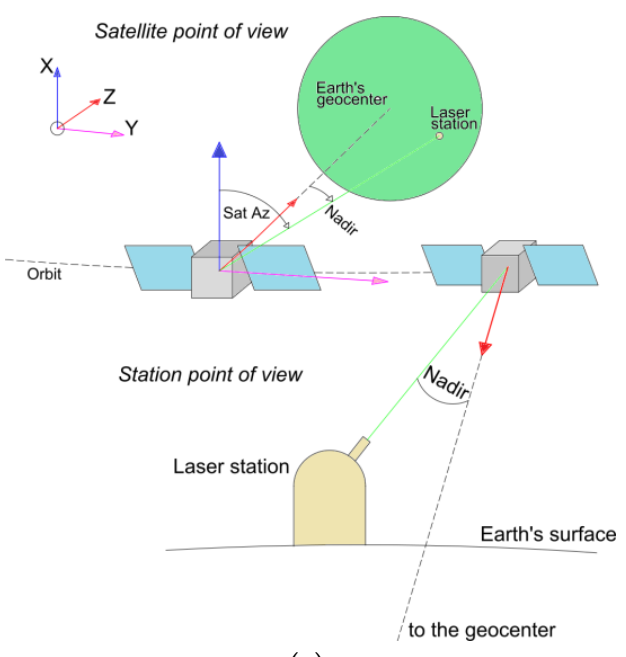

(a)

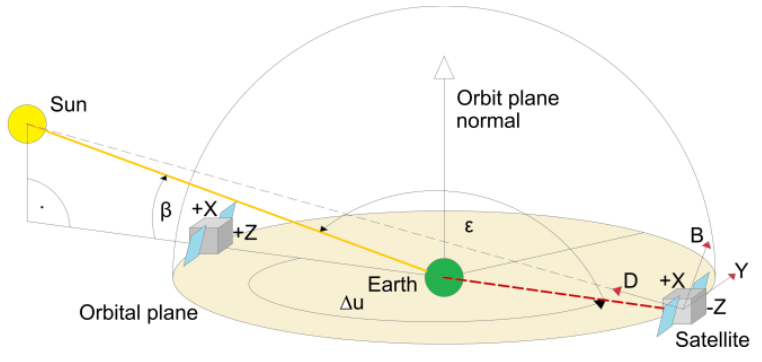

(b)

Figure 1. (a) Satellite-based reference frame; and (b) relative geometry of the Earth, satellite and the Sun showing the elevation angle of the Sun over orbital plane $\beta$, argument of the satellite latitude with respect to the Sun $\Delta u$ and the elongation angle $\varepsilon$. 


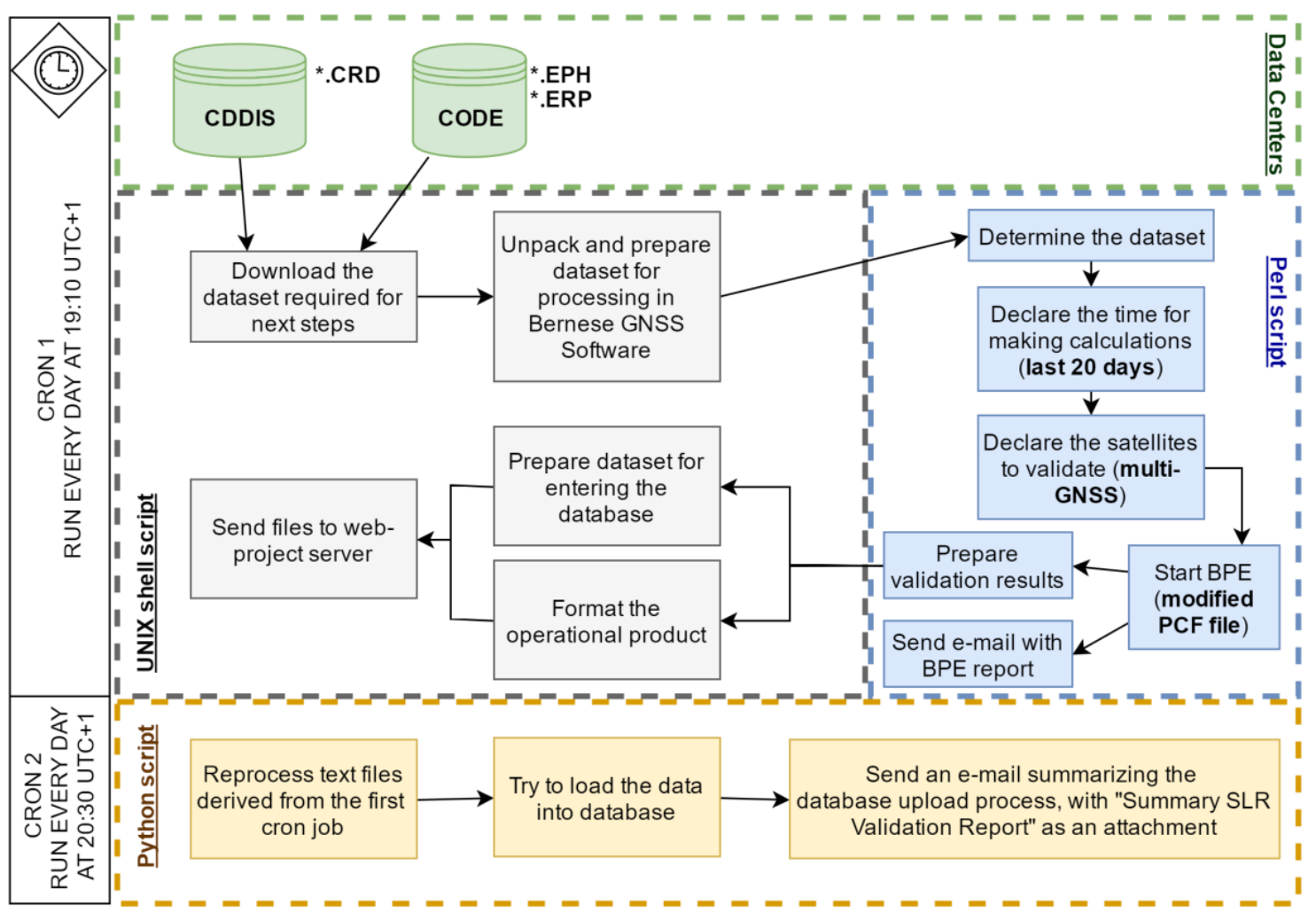

Figure 2. Flow scheme for processing of GOVUS daily campaign. Abbreviations used: CDDIS, Crustal Dynamics Data Information System; PCF, Processing Control File; BPE, Bernese Processing Engine.

The dataset necessary for validation consists of: (1) dataset of SLR normal points (delivered by CDDIS [42]); (2) microwave-based discrete satellite positions (EPH files with orbit ephemerides); and (3) GNSS-derived Earth Rotation Parameters (ERP file). First, the files of Normal Points are converted into separated RINEX files including normal points and meteorological data in turn. In parallel, the continuous 1-day orbits are fitted to the discrete satellite positions from the EPH file. The arc-fit strategy is consistent with the official CODE's MGEX solution processing [5] in an aim to correctly restore the orbit. Minor differences in orbit modeling are absorbed by estimating stochastic pulses in three orbital directions. The summary of observation modeling and the strategy of parameters estimation is included in Table 1.

The dataset is processed in such a manner to receive SLR residuals with no additional parameter estimation, i.e., with fixing station coordinates, to the ILRS realization of ITRF2014, i.e., SLRF2014, and fixing both orbits and ERP to CODE values. The range measurements are corrected by tidal station displacements, troposphere refraction, general relativity and other corrections recommended by the International Earth Rotation and Reference Systems Service (IERS) 2010 Conventions. Finally, the dataset is subject to the initial analysis, which summarizes the aggregated statistics for each station-satellite pair grouped according to the particular day of observation and stored in a summary file.

The output from the validation process consists of a detailed list of SLR residuals together with information about laser station, satellite, residual value and time. Additionally, the angular characteristic of each laser measurement is included, thus we can investigate the residuals in very broad spectrum of geometrical dependencies: (1) two angles as seen from SLR station point of view: azimuth and elevation; (2) two angles as seen from the satellite: azimuth and nadir (Figure 1a); and (3) two angles describing the relative location of the Sun, the satellite, and the Earth in the time of observation: satellite argument of latitude with respect to the argument of the Sun $(\Delta u)$ and the Sun elevation angle above the orbital plane $(\beta)$ (see Figure $1 b$ ). The computational schema is hard-wired 
for fully automated data reprocessing using BPE [39]. The web-application is prepared for conducting the automated validation process with a daily routine. For this purpose, a time-based job scheduler, based on cron, combined with dedicated UNIX shell and Python scripts, was prepared. The workflow is presented in Figure 2. The main limitation in delivering near-real time SLR validation products comes from the frequency of the CODE MGEX orbit products being available. CODE MGEX products are being made public with the latency of about two weeks.

Table 1. Summary of observation modeling and parameter estimation strategy.

\begin{tabular}{cc}
\hline & SLR Validation \\
\hline $\begin{array}{c}\text { Software } \\
\text { GNSS considered } \\
\text { Considered orbit providers } \\
\text { Validation routine } \\
\text { Time span }\end{array}$ & $\begin{array}{c}\text { Bernese GNSS Software 5.2 with modifications [39] } \\
\text { GPS, GLONASS, Galileo, BeiDou-2 MEO and IGSO, QZSS } \\
\text { CODE } \\
\text { daily }\end{array}$ \\
\hline & since DOY 146/2012 (GPSWEEK 1689) \\
\hline Reference frame & Models for Processing \\
Solid Earth tides & SLRF2014 with postseismic deformations from ITRF2014 [13] \\
Ocean tide & IERS 2010 Conventions [35] \\
Troposphere & FES2004 [43] \\
Relativity & Mendes and Pavlis 2004 [11] \\
LRA offsets & IERS 2010 Conventions [35] \\
\hline & according to the recommendations of the ILRS [7] \\
\hline Satellite positions & CODE MGEX ephemerides \\
Carth Rotation Parameters & CODE MGEX ERP files \\
Albedo model & Orbit Reconstruction \\
Antenna thrust & GPS, GLONASS, Galileo, QZSS applied since 08/2017; BeiDou not applied \\
Attitude model & GPS, GLONASS, Galileo, QZSS applied since 08/2017; BeiDou not applied \\
SRP model & yaw steering assumed for all satellites \\
Stochastic pulses & ECOM2 \\
\hline
\end{tabular}

\subsection{Structure and Functionality}

The main tasks of the developed service are to: (1) store archival and current information about the ILRS laser stations and multi-GNSS satellites; (2) store the multi-GNSS microwave orbit validation results using SLR; (3) allow for fast and advanced online analyses on the stored dataset; (4) provide an autonomous computing center; and (5) generate up-to-date dataset and reports. Therefore, the GOVUS system consists of advanced database system, seven main modules of the web-based application and server-side, and time-scheduled computational scripts. The client-side of the application has been developed using Django Framework.

The database system responsible for storing and managing data is the PostgreSQL, which provides a good performance for the query requirements and allows for performing spatial analyses using PostGIS extension. Currently, no spatial analyses are available in GOVUS, but the core database system is prepared for supporting the future extension of the service. Four major tables are publicly available and directly used in data analyses: (1) observations (SLR residuals); (2) laser stations; (3) multi-GNSS satellites; and (4) time-variables for multi-GNSS satellites (see Figure 3):

- The table called "observation" contains one record for each SLR residual row resulted from the validation process. Additionally, local time of observation is calculated, in reference to the related station's longitude.

- The table called "station" describes the features of each single SLR station including information about: code (4 letter shortcode), id (4-digits number unique for the station), country, tectonic plate, operational sub-network, CDDIS number, coordinates, primary wavelength, detector type, signal processing, mode of operation, timer type, max repetition rate, laser power, laser type, beam diameter, pulse width, max energy and date of update. All information is filled in based on the official ILRS stations site logs.

- The table called "satellite" describes features of each satellite from all systems, GPS, GLONASS, Galileo, BeiDou and QZSS, and contains information about: Satellite Vehicle Number (SVN) (unique for each satellite but not generally structured), NORAD, COSPAR, slot in orbital plane, 
orbital plane number, satellite type/generation, satellite system, information about the LRA (size, shape, type of coating, number of retroreflectors in array, and dimension of a single retroreflector), and information about the orbit (semi-major axis, altitude, revolution period, inclination, and eccentricity)

- The table called "satellite_tv" (satellites' time variables) describes the time-dependent features of each satellite such as: SVN (identifier of the satellite, to which variables are referred), PRN (Pseudo Random Noise, which is different for each satellite in particular system and indicates the channel number of the satellite microwave signal transmission; however, the satellite can be associated with different PRN numbers during its lifetime), generation (chronological number of change for the particular satellite), time interval for the time variables, microwave antenna offset, and LRA offset in reference to the satellite center of mass (CoM).

The application allows for creating many types of advanced and interactive plots. These features are ensured by using external JavaScript libraries (mainly Highcharts.js) dedicated for data-processing and data-visualizing. A complete list of the libraries and the terms of its licenses are attached in "About" subpage of the GOVUS web-application.

To logically divide the service's functionality between tools, separate modules were prepared: (1) Plot Analyses; (2) Table List; (3) Station Statistics; (4) Satellite Statistics; (5) Report module; (6) Interactive map; (7) Tools; and (8) GOVUS SQL Explorer. Almost every dataset chosen by the user may be converted into the *.CSV format and downloaded. The dataset is ready to be reprocessed in more advanced external software. All plots can be freely downloaded in raster $\left({ }^{*}\right.$.png and ${ }^{*}$.jpeg) or vector $\left({ }^{*}\right.$. svg and ${ }^{*}$.pdf) file formats, thus the user may adjust selected plots to their needs.

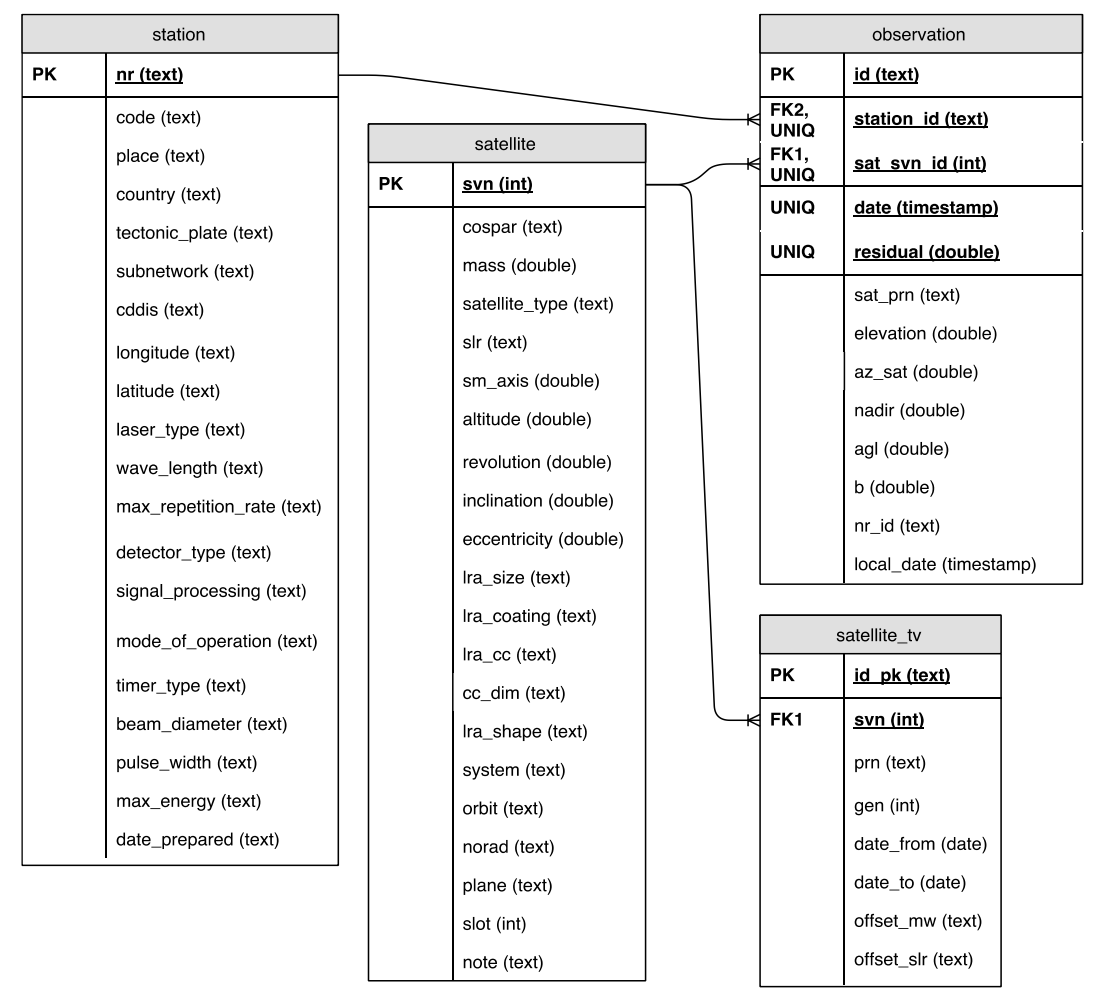

Figure 3. Partial scheme of the GOVUS database, used in the web application. Abbreviations used: PK, primary key; FK, foreign key, UNIQ, unique value; int, integer; double, double-precision floating-point number. 


\subsection{Capabilities of GOVUS with Respect to the Critical Issues of SLR and Multi-GNSS}

As GOVUS should serve to the scientific community, it is essential to point out the current issues of both the multi-GNSS orbit determination and the SLR tracking network. Most of the current problems with the homogenous multi-GNSS orbit determination are related to the lack of proper models, which could entirely reduce the effects of most important non-gravitational accelerations such as SRP, antenna thrust and both thermal radiation from the Earth and Earth's albedo, as well as proper modeling of satellite attitudes for non-yaw-steering events $[1,44,45]$. Constant monitoring and independent validations are advised by both the MGEX and IGS authorities to help in the description of satellites' perturbations. Moreover, the existence of the orbit-modeling issues may reflect in dependencies between the orbit quality and the elevation angle of the Sun above the orbital plane, the elongation angle, or the latitude of the satellite with respect to the Sun [1]. However, the impact of those dependencies is still not fully understood and eliminated, so that the nature of the perturbations should be constantly investigated. When using GOVUS, the user can restrict the analysis to the desirable satellite system, group of potentially similar objects (common orbital planes) or to focus on particular satellites. According to the last IGS report [43], the analyses of the single satellites are a decent action for the future MGEX development (see Table A2).

The major issue of SLR tracking is the heterogeneity of stations' efficiency and accuracy. The stations generate a different number of Normal Points (see Table A1) and are unevenly distributed across the globe [46]. Therefore, the SLR network struggle with the deficiencies in the geometrical distribution of measurements. Regional satellite systems such as QZSS and partly BeiDou-2 are most affected by this fact.

The station's performance is dependent on the installed equipment as well as overall system integration, compatibility and proper working of each device. Each technical change or unexpected event [47], which happen at the station, may affect the dataset. GOVUS allows for cross-validation of the log of stations' events and detection of anomalies in the time series of SLR residuals. When performing the SLR validation, the user should be conscious about the station-related issues to not propagate SLR systematic errors to the evaluation of orbit quality. Thanks to the near-real time functionality all discontinuities or degradation of station products' quality may be immediately reported and excluded from analyses.

The near-real time functionality may warn the multi-GNSS community about the unexpected behavior of particular satellites. During the last two years, multi-GNSS users realized that a growing number of GLONASS satellites have some problems (e.g., SVN 737 or 736) [1,48] (see Figure 4). The issue may arise from many possible satellite-related reasons, such as attitude sensors, shifted center of mass with respect to satellite reference frame origin, or a change of the antenna offset. The possibilities of upcoming problems with other GLONASS satellites or any other anomalistic behavior of multi-GNSS satellites can be noticed in near-real time thanks to GOVUS. Such functionality is especially important for users of multi-GNSS post-processed products. This knowledge allows for excluding from their processes those satellites, whose orbit quality exceeds the desired accuracy threshold. The constellation of multi-GNSS is still in constant development. New GNSS satellites complement the deficiencies in constellations or exchange the outdated buses every couple of months. New satellites represent often the new type or block, which may differ from other satellites in shape, size, mass or power of signal transmission. The internal satellite diversity within a satellite system is sufficiently large to impose a problem for regular users of multi-GNSS. GOVUS enables the users to evaluate the orbit quality in the context of both integrity of satellite bus and correctness of used orbit models (e.g., SRP, albedo). 


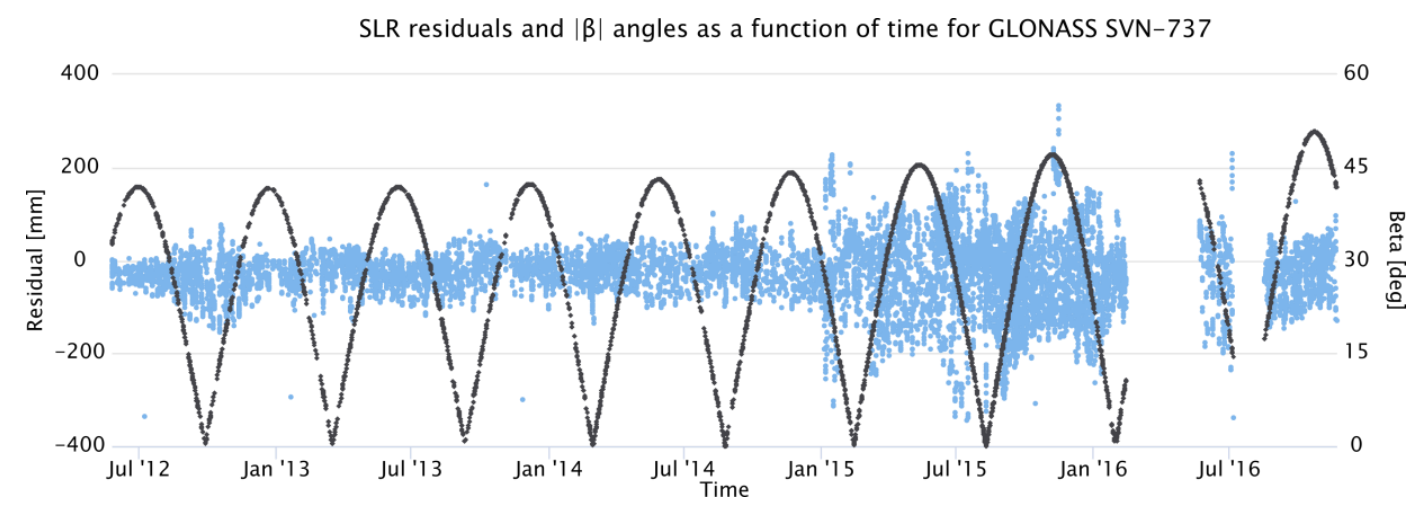

Figure 4. SLR residuals as a function of time; grey dots represents the change of $|\beta|$ angles in time.

\subsection{Tools for Identification of GNSS Satellites in GOVUS}

Currently, there is no standardized and official numbering system for the satellites. Depending on the scientific community or the satellite system characteristics, other numbering systems are preferred. Those mostly used include SVN, PRN, COSPAR designation, and NORAD/Satellite Catalog. In the case of the GOVUS system, SVN numbers are preferred, however, being aware of the problem of the diversity of the common nomenclature, helpful tools have been developed:

- $\quad$ PRN2SVN allows for checking which satellites (SVN) were related with the particular broadcast channel (PRN) in the selected range of time.

- $\quad$ SVN2PRN informs to which channel (PRN) from the satellite system a particular satellite (SVN) was assigned.

- CONSTELLATION shows the complete list of the satellites (SVN) which constituted the constellation of the particular satellite system in the specified date.

\subsection{GOVUS SQL Explorer}

Despite a very wide range of analyses that may be performed, the web-application does not provide answers to all possible questions that a user could ask; therefore, the GOVUS SQL Explorer was created. This additional module works independently to the service and allows users to run raw SQL queries on the GOVUS database (Figure 3). For safety reasons, the module availability is restricted to authorized users, however, anyone can ask for a private account. The user can run any SQL query in read-only mode.

SQL Explorer aims to make the flow of data between users easy, while creating some kind of community at the same time. Users can write and share SQL queries, preview the results in the browser or download the query's results in editable *.CSV file. Every single module usage is registered; moreover, executed queries are assigned to the user. Thus, expectations raised by the users are monitored and affect the future service's improvements.

\section{Results}

This section summarizes the results of the SLR validation of MGEX CODE's orbit for the period January 2016-August 2017 performed using GOVUS. The results for the period January 2016-June 2016 were confronted with the latest articles on multi-GNSS orbit quality [1]. We show changes of validation results after the switch of the reference frame from SLRF2008 to SLRF2014. Moreover, results for period January 2016-August 2017 were presented for the particular types of satellites GLONASS M, $\mathrm{K} 1, \mathrm{M}+$, Galileo FOC, IOV, BeiDou IGSO, MEO and QZSS. Galileo FOC satellites, which were launched in 2014 into extended, highly eccentric orbits (marked as FOC ${ }^{*}$ ), have been separated from the other FOC satellites. We also indicate different approaches to the selection of laser stations in the validation 
process. This section highlights the actual place for GOVUS within MGEX activities in the context of orbit validation and proposes the directions for future developments.

\subsection{Assessment of the Orbit Quality}

Orbit quality assessment based on the results coming from the SLR validation is the most obvious and popular application of the SLR observations to the GNSS constellation. The results of such kind of analyses are systematically published in reference to the different orbit models [1,24-28,49-57]. The major innovation introduced by the GOVUS system is the near-real time of calculations and a remarkable ease of repeatability of performed analyses for every user. Consequently, the user can perform analyses on the daily updated dataset, without any processing efforts.

The latest, complex SLR validation results were published in [1] for the period 1 January-30 June 2016. In June 2017, the ILRS instructed all ACs to change the reference frame of the laser station coordinates in their processing routines from the SLRF2008 to the new release of SLRF2014. We reprocessed all the results using a new processing routine with SLRF2014. Therefore, we can compare the SLR validation results delivered by [1] and GOVUS in the corresponding period and evaluate the impact of the change. Table 2 provides a comparison between the mean offsets and standard deviations provided in [1] and delivered by GOVUS. Initially, we exclude gross outliers, which exceed $1000 \mathrm{~mm}$ for BeiDou IGSO and QZSS, $500 \mathrm{~mm}$ for BeiDou MEO and $250 \mathrm{~mm}$ for other types of satellites.

Table 2. SLR residual offsets (AVG) and standard deviations (STD) for the period 1 January-30 June 2016. Values in $\mathrm{mm}$.

\begin{tabular}{|c|c|c|c|c|c|c|c|c|c|c|c|c|}
\hline \multirow{3}{*}{ Source } & \multirow{2}{*}{\multicolumn{2}{|c|}{$\begin{array}{c}\text { GLONASS } \\
\text { ALL }\end{array}$}} & \multicolumn{4}{|c|}{ Galileo } & \multicolumn{4}{|c|}{ BeiDou } & \multirow{2}{*}{\multicolumn{2}{|c|}{$\begin{array}{c}\text { QZSS } \\
\text { ALL }\end{array}$}} \\
\hline & & & \multicolumn{2}{|c|}{ IOV } & \multicolumn{2}{|c|}{ FOC } & \multicolumn{2}{|c|}{ MEO } & \multicolumn{2}{|c|}{ IGSO } & & \\
\hline & AVG & STD & AVG & STD & AVG & STD & AVG & STD & AVG & STD & AVG & STD \\
\hline $\operatorname{COM}(\mathrm{MGEX}) *$ & 5 & 50 & -43 & 45 & -35 & 43 & -34 & 65 & -28 & 145 & -20 & 260 \\
\hline COM (GOVUS) ** & -12 & 36 & -45 & 38 & -31 & 34 & -12 & 52 & -19 & 132 & -18 & 248 \\
\hline
\end{tabular}

The results delivered by MGEX and GOVUS are comparative. The main difference is visible for GLONASS satellites. The core statistics for MGEX and GOVUS equal $5 \pm 50$ and $-12 \pm 36 \mathrm{~mm}$, respectively. After the change of the reference frame, the standard deviation of validation results improved for each satellite system: 50 to 36,45 to 38,43 to 34,65 to 52,145 to 132 and 260 to $248 \mathrm{~mm}$, for GLONASS, Galileo IOV, FOC, BeiDou MEO, IGSO and QZSS, respectively.

Table 3 provides validation results for the extended period 1 January 2016-31 July 2017, taking into account various sets of SLR stations: (1) stations equipped with different detectors [58] (CSPAD, MCP, and PMT); (2) TOP10 stations; and (3) all available stations. Initially, we exclude gross outliers, which exceed $500 \mathrm{~mm}$ for all SLR residuals. As TOP10 we chose stations, which deliver more than 1000 normal points of stable observations, i.e., with no discontinuities in the time series in the analyzed period and did not indicate any dependencies between SLR residuals and the observational frame with respect to the azimuth and elevation angle. The list of TOP10 stations includes: Graz 7839, Herstmonceux 7840, Mount Stromlo 7825, Wettzell 7827 and 8834, Yarragadee 7090, Matera 7941, Greenbelt 7105, Brasilia 7407 and Potsdam 7841. 
Table 3. SLR residual offset (AVG) and standard deviations (STD) for the period 1 January 2016-31 July 2017. Results divided between different sets of laser stations. All values in $\mathrm{mm}$. Included groups of satellites (SAT): BeiDou IGSO and MEO, Galileo FOC, FOC* launched on the extended highly eccentric orbit, IOV, GLONASS K1, M, M+ and QZSS QZS-1.

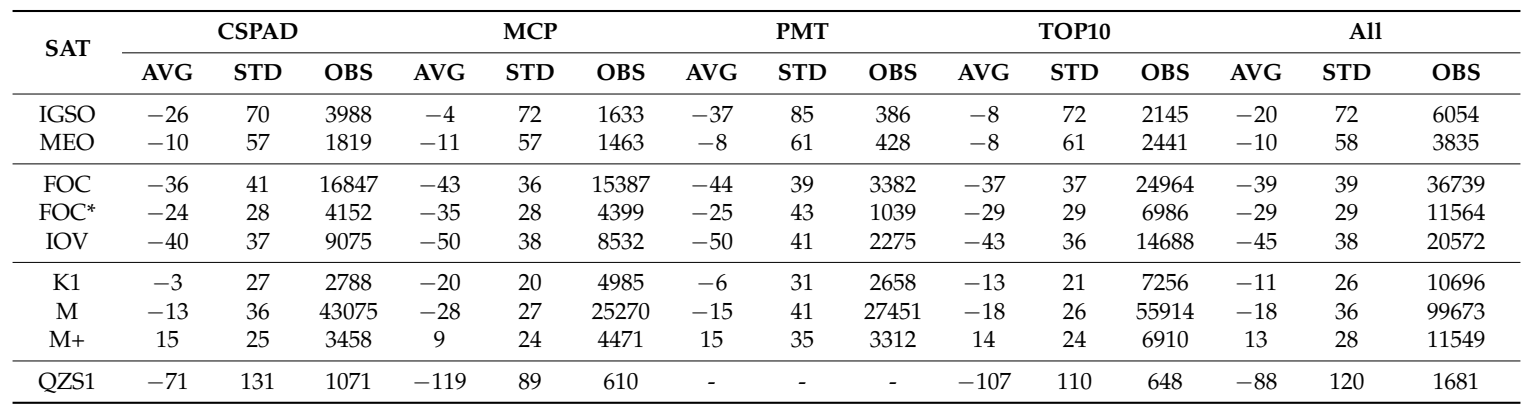

Table 3 indicates the heterogeneity of SLR measurements to the multi-GNSS satellites, i.e., the dependency on the chosen dataset of laser stations. Mean offsets for FOC, FOC*, IOV, K1, $\mathrm{M}$ satellites are smaller for single-photon stations equipped with CSPAD detectors in comparison to multi-photon stations equipped with MCP or PMT detectors. For instance, the mean offset equals -36 $\pm 41,-43 \pm 36$, and $-44 \pm 39$ for Galileo FOC and $-3 \pm 27,-20 \pm 20$, and $-6 \pm 31$ for GLONASS-K1, for CSPAD, MCP, and PMT detectors, respectively.

The MCP and the PMT stations are more vulnerable to satellite signature effect [33,50,54], hence the dependency on the incident angle should be larger and negative (see Figure 5). The histograms of SLR residuals to GNSS for selected MCP and PMT stations are asymmetrical (see Figure 6). The histograms are broader on the left side creating some form of a tail, which may confirm that MCP and PMT detectors are affected by the satellite signature effect. The multi-photon detectors are not able to register full range of returning photons. For high incidence angles, many of registered photons return after the reflection from the nearest edge of the flat LRA. The core statistics for TOP10 stations are very similar to the dataset containing all stations, however, the standard deviation decreases, especially for GLONASS satellites: 26 to 21, 36 to 26 and 28 to $24 \mathrm{~mm}$, for K1, M and M+, respectively. Some of the most efficient Russian laser stations such as 1868 Komsomolsk, 1887 Baikonur, or 1886 Arkhyz indicate inexplicable range bias or a high value of the standard deviation. The laser stations in Shanghai 7821 and Changchun 7827 show a dependency between the values of SLR residuals and the elevation angle of performed observation (see Table A1). Such biases and dependencies may affect the validation results as in the case of abovementioned comparison. Further statistics related to the particular stations are attached in the Table A1 where three types of characteristics are shown: (1) general statistics including the mean, median and standard deviation of the SLR residuals, as well as the number of observations; (2) dependency between SLR residuals and the nadir angle; and (3) dependency between SLR residuals and the elevation angle.

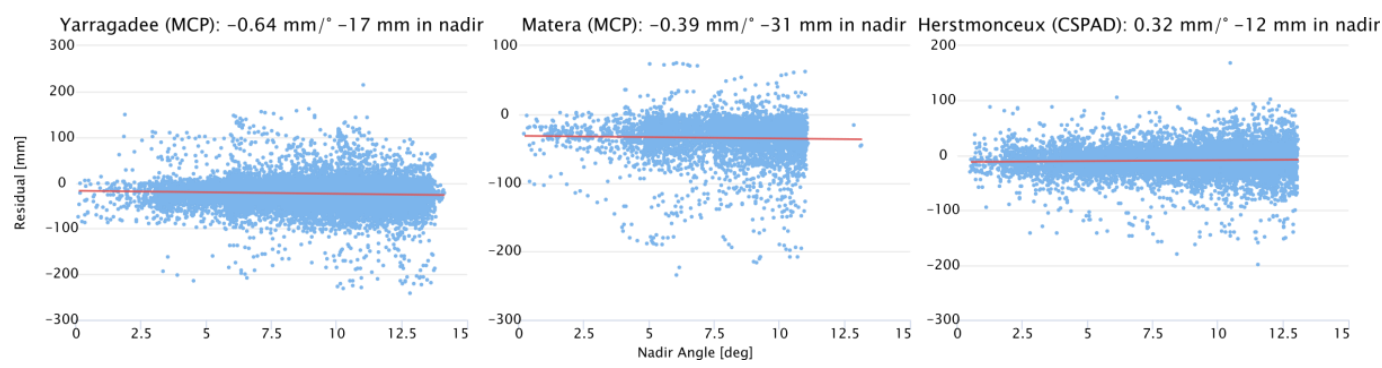

Figure 5. SLR residuals to GLONASS-M satellites as a function of the nadir angle for selected SLR stations. Description of a title: place, detector type, regression slope of SLR residuals as a function of nadir angle, bias in nadir. 


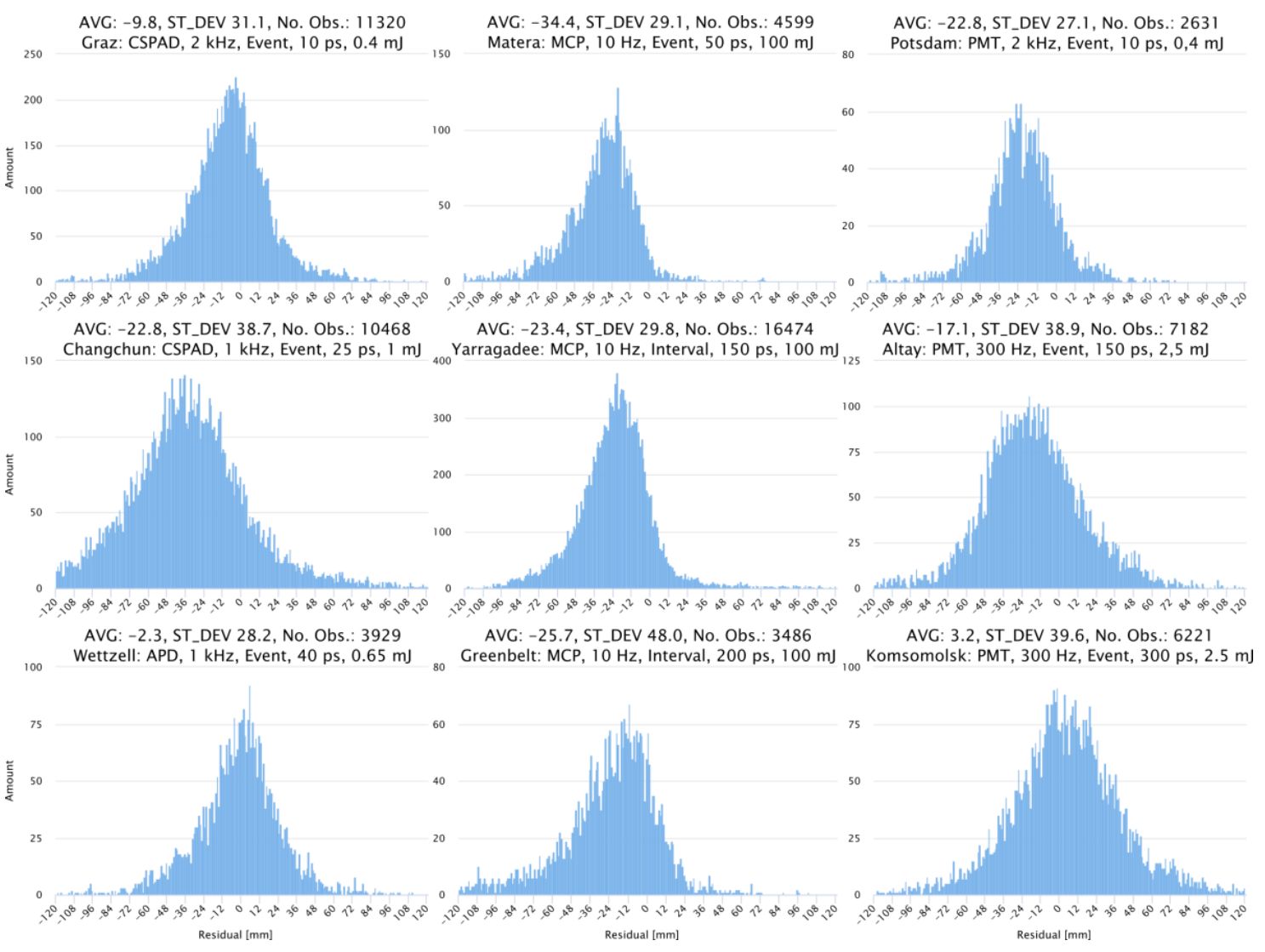

Figure 6. Histograms of SLR residuals related with particular laser stations; Dataset from August 2015-July 2017, consisted of only SLR residuals related to GLONASS-M satellites with uncoated LRA. Abbreviations used: AVG, average; ST_DEV, standard deviation; No. Obs., number of observations. Station characteristics included in a title in order: place, detector type, max repetition rate $(\mathrm{Hz})$, timer type, pulse width (ps), max energy (mJ).

Statistics for different types of satellites differ even within the same satellite system (see Table 3 , TOP10). The mean offset for Galileo FOC satellites, which equals $-37 \mathrm{~mm}$ is smaller than the offset for Galileo IOV satellites, which equals $-43 \mathrm{~mm}$. Moreover, the offset for Galileo FOC satellites, which were launched into extended highly eccentric orbits (SVN 201 and 202), is smaller than for the other Galileo FOC satellites. The mean offset for GLONASS-K1 equals $-13 \pm 21$ and is smaller than for GLONASS-M satellites, for which the offset is $-18 \pm 36 \mathrm{~mm}$. The offset for GLONASS-M+ equals $13 \pm 28 \mathrm{~mm}$ and clearly diverges from the other GLONASS satellites. The GLONASS M+ is the only GLONASS satellite with the regular mean positive offset of SLR residuals (see Table 3 and Table A2).

The dependency between SLR residuals to multi-GNSS and the local time of observations can also be analyzed in the GOVUS service (see Figure 7). Only some of SLR stations are able to track GNSS satellites in the daylight. The local time of measurements has an impact on the values of residuals and the number of observations collected by SLR stations. The station Graz (7839), operating in the low-energy regime, delivers more observations at night. In contrary, there is no difference in the number of observations performed during the daytime and at night in Yarragadee (7090), however the mean SLR residuals for observations collected at night are nearly twice as large as in the daytime. 


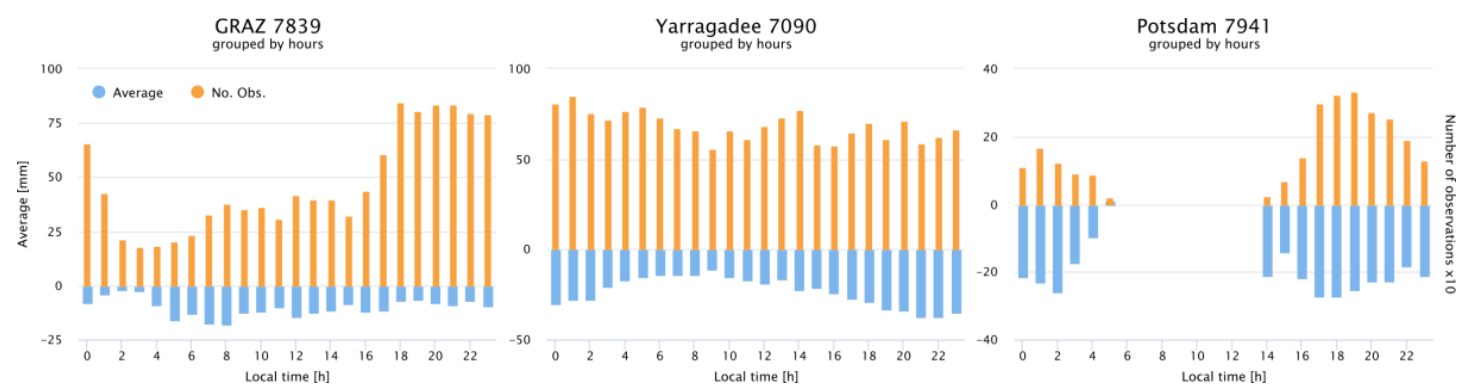

Figure 7. Relationship between local time on the laser station and both average SLR residuals and number of generated observations on selected laser stations; Dataset from October 2015-July 2017, consisted of only SLR residuals related to GLONASS-M satellites with uncoated LRA. Abbreviations used: No. Obs., number of observations.

The quality and quantity of SLR observations made by various stations are unquestionably different. Observations collected by particular stations equipped with different detector types should be individually analyzed. The problem of individual station behavior should lead to attempts of modeling the systematic biases and residual dependencies as an aim to improve both the overall SLR dataset as well as the overall geometry of observations, which is one of the main issues of the past, current, and future SLR network. Only a certain proportion of the current dataset of SLR residuals to GNSS satellites seems to be clearly unbiased and provides clear information about the orbit quality. Lack of knowledge and consciousness about the particular stations' performance and the dependency arising from, e.g., the type of the detector, may lead to misjudgment of the whole orbit quality or single satellite behavior as the range biases can achieve values of several centimeters.

Since 6 August 2017, CODE orbits include the antenna thrust and albedo models for Galileo and QZSS satellites, in addition to previously included GPS and GLONASS models. The first visible differences in SLR residuals caused by this change are presented in Table 4. The month preceding the change was compared with the month following the change. Despite a limited time span, the improvement is clearly visible (see Figure 8). The mean offset decreased mostly for all Galileo satellites. The offsets have changed from -38 to 0 , from -44 to -1 , and from -57 to $-8 \mathrm{~mm}$, whereas standard deviations are changed from 40 to 20, from 18 to 23, and from 30 to $21 \mathrm{~mm}$ for Galileo FOC, FOC* and IOV, respectively (see Figure 8). The improvement of the core statistics for GLONASS-M and $\mathrm{K} 1$ is smaller than for Galileo satellites but also noticeable (see Table 4). The increase of the standard deviation for GLONASS-K1 is caused by the individual problems of the satellite at the end of August 2017. Some anomalous positive biases of $+30 \mathrm{~mm}$ are also visible for GLONASS-M+.

Table 4. SLR residual offset (AVG) and standard deviations (STD) for the period 1 July 2017-31 August 2017. Values are in mm. Abbreviations used: AVG, average; STD, standard deviation; OBS, number of observations.

\begin{tabular}{cccccccc}
\hline \multirow{2}{*}{ System } & \multirow{2}{*}{ Type } & \multicolumn{3}{c}{ July 2017 } & \multicolumn{3}{c}{ August 2017 } \\
\cline { 3 - 7 } & & AVG & STD & OBS & AVG & STD & OBS \\
\hline \multirow{3}{*}{ GALILEO } & FOC & -38 & 40 & 1592 & 0 & 20 & 1880 \\
& FOC $^{*}($ ext. $)$ & -44 & 18 & 354 & -1 & 23 & 361 \\
& IOV & -57 & 30 & 609 & -8 & 21 & 714 \\
\hline \multirow{3}{*}{ GLONASS } & K1 & -18 & 16 & 545 & 8 & 61 & 560 \\
& $\mathrm{M}$ & -19 & 26 & 3486 & -9 & 25 & 3643 \\
& $\mathrm{M}+$ & 12 & 23 & 288 & 30 & 16 & 343 \\
\hline
\end{tabular}




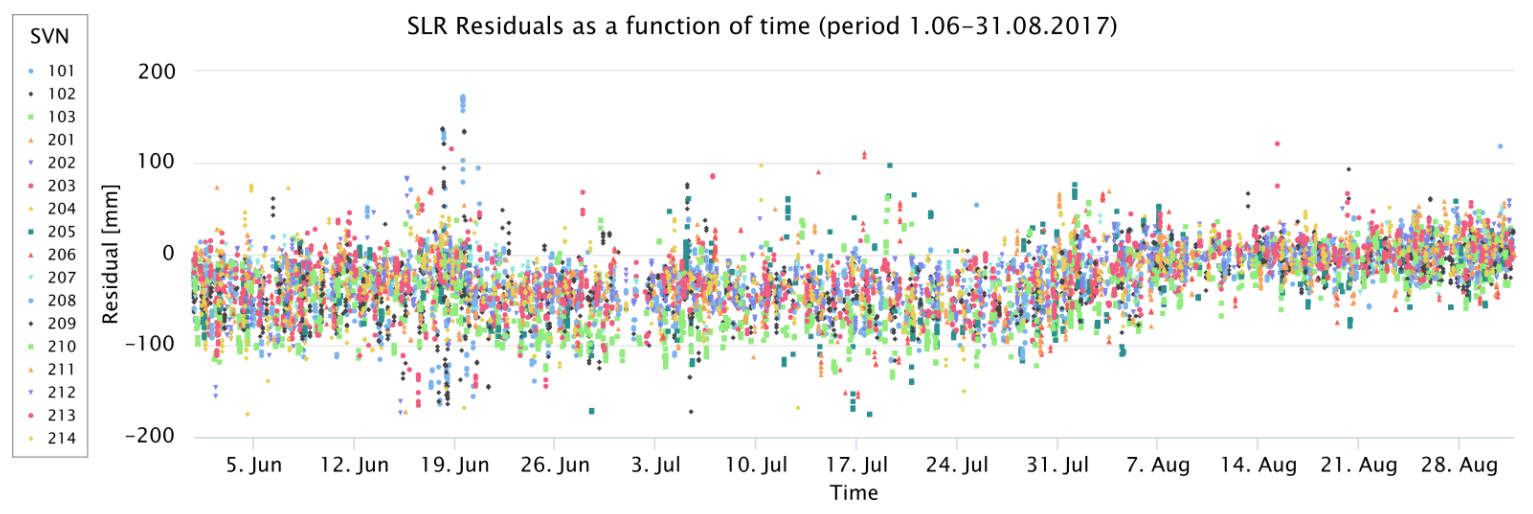

Figure 8. SLR residuals as a function of time for Galileo satellites in period 1 June 2017-31 August 2017.

\subsection{Discussion on Possible Directions of the System Development for the Future}

The benefits from SLR tracking of the multi-GNSS constellation are constantly being confirmed: improvement of the laser station coordinate determination [59], contribution to GGOS activities [60], improvement of the quality of multi-GNSS satellites, as well as clock synchronization and confirmation of relativistic effects acting on Galileo satellites in eccentric orbits [61]. However, a limited number of ACs routinely process SLR observations to GNSS in their operational products. Currently, GOVUS delivers ready-to-use online tools and the up-to-date dataset of SLR residuals. The major advantage of the system is a favorable ratio of time, which is needed to perform a plethora of multi-GNSS orbit analyses. We are open to ideas of new tools that might potentially be developed into the service. The computational schemes of the GOVUS system are currently focused on precise orbit products delivered by CODE in the frame of the MGEX project; however, other orbit solutions can be included into the validation process, including new satellite types and results provided by MGEX ACs.

Nowadays, we observe the gradual improvement of MGEX orbit solutions. In the upcoming years, MGEX contributors will probably eliminate critical issues of precise orbit determination such as dependencies in a Sun-Earth-satellite frame or improvement of common multi-GNSS models, e.g., SRP. Finally, a full integration of multi-GNSS will come to the official IGS processing routine. Public users will be increasingly interested in using multi-GNSS products. The GOVUS service may become a great tool for MGEX contributors (especially ACs) as well as for laser stations. The next efforts on the development of GOVUS will be focused on providing necessary real-time functionality for users of multi-GNSS data and products. We plan to implement spatial tools, which could inform the user about the quality of satellite orbits, which are visible in a specific period from a specific place on the Earth. The GOVUS should also monitor the exact spatial coverage of SLR measurements to the GNSS satellites.

\section{Conclusions}

The fully operational on-line service called GOVUS has been delivered to allow for analyzing and visualizing results of SLR validation of microwave-based multi-GNSS orbits. The GOVUS system not only fulfills a function of a web tool, but also acts as the advanced computational center, which generates unique operational products, delivered every day to the end-user. GOVUS provides information on multi-GNSS orbit quality, changes of parameters in the GNSS constellations, characteristics of SLR ground segment, as well as on quality and quantity of SLR observations to multi-GNSS constellations. The service contributes to the development of multi-GNSS in the frame of the IGS MGEX project. This paper describes and demonstrates examples of the analyses that can be generated using the service. The comparison with the latest literature [32] has confirmed the reliability of the results. The results for the particular types of satellites in the period January 2016-August 2017 equal: $-13 \pm 21,-18 \pm 26$ and $14 \pm 24 \mathrm{~mm}$, for GLONASS K1, M and M+, respectively; $-43 \pm 36$, 
$-37 \pm 37,-29 \pm 29 \mathrm{~mm}$, for Galileo IOV, FOC and FOC*, respectively; $-8 \pm 72$ and $-8 \pm 61 \mathrm{~mm}$, for BeiDou IGSO and MEO, respectively; and $-107 \pm 110 \mathrm{~mm}$ for QZS-1. The offset for all Galileo satellites decreased after the implementation of antenna thrust and albedo models to $-8 \pm 21,0 \pm 20$, and $-1 \pm 23 \mathrm{~mm}$, for Galileo IOV, FOC and FOC*, respectively.

All of the examples presented in this paper are easily reproducible by any user. It highlights the usefulness of the service and the potential given to the scientific progress in the development and improvement of the multi-GNSS products and applications. As of today, the MGEX products do not contain information about the quality of the orbit products; therefore, GOVUS aims at filling this gap. As presented in Section 3, there are differences in orbit quality between each system of the multi-GNSS constellation, or even the particular types of the satellite are significant, hence the access to near real-time results of SLR validation of these products is beneficial for the multi-GNSS community. It may be very useful for all multi-GNSS users to employ this easily accessible database, which includes information about the multi-GNSS satellite parameters, such as the orbital plane, antenna and laser retroreflector offsets, slot in the orbital plane, type and generation, as well as historical changes of the assignation of satellite to PRN numbers and channels for different GNSS spacecraft (see Table A3). On the other hand, the GOVUS system serves as the quality control system for the laser stations and the ILRS authorities, which are informed about the derogation from the expected efficiency and accuracy of the measurements.

Supplementary Materials: The final product is operating in a fully operational stage, all over the world, without any restrictions for desktop and mobile users. The link to GOVUS service is available at [62,63]. A complete list of the libraries and the terms of its licenses are attached in "About" subpage of the GOVUS web-application [63].

Acknowledgments: The ILRS and IGS are acknowledged for providing SLR and GNSS data. The SLR and GNSS stations are acknowledged for a continuous tracking of the geodetic satellites as well as for providing high-quality SLR and GNSS observations. K. Sośnica and G. Bury are supported by the Polish National Science Centre (NCN), grant No. UMO-2015/17/B/ST10/03108. R. Zajdel and K. Sośnica are funded by "EPOS-European Plate Observing System" co-financed by the European Union from the funds of the European Regional Development Fund (erdf), grant No. POIR.04.02.00-14-A003/16-00.

Author Contributions: R. Zajdel developed the described system, performed the data analysis and wrote the paper; K. Sośnica implemented the modification in software, performed the SLR validation process, edited the manuscript, and provided valuable insights; and G. Bury performed the SLR validation process and provided valuable insights.

Conflicts of Interest: The authors declare no conflict of interest. 


\section{Appendix A}

Table A1. Statistics for SLR stations, including characteristics of SLR residual as a function of the nadir angle and the elevation angle, data covers the period August 2015-July 2017, including SLR residuals to GLONASS-M satellites with uncoated LRA. Abbreviations used: NR, identification number of laser station; MMR, maximum repetition rate (Hz); PW, pulse width (ps); WL, wavelength (nm); ME, maximum energy (mJ); AVG, average (mm); STD, standard deviation (mm); Slope E, regression slope of SLR residuals as a function of elevation angle $\left(\mathrm{mm} /{ }^{\circ}\right)$; Zenith, bias in zenith $(\mathrm{mm})$; Slope $\mathrm{N}$, regression slope of SLR residuals as a function of nadir angle $\left(\mathrm{mm} /{ }^{\circ}\right)$; Nadir, bias in nadir $(\mathrm{mm})$; Obs. No., number of observations.

\begin{tabular}{|c|c|c|c|c|c|c|c|c|c|c|c|c|c|c|}
\hline NR & Detector & Timer & MRR (Hz) & PW (ps) & WL (nm) & ME (mJ) & AVG (mm) & Median (mm) & STD (mm) & Slope $\mathrm{E}\left(\mathrm{mm} /{ }^{\circ}\right)$ & Zenith (mm) & Slope $\mathrm{N}\left(\mathrm{mm} /{ }^{\circ}\right)$ & Nadir (mm) & Obs. No. \\
\hline 7839 & CSPAD & Event & 2000 & 10 & 532 & 0.4 & -9.7 & -7.6 & 31.1 & 0.08 & -12.8 & 0.44 & -13.5 & 11320 \\
\hline 7237 & CSPAD & Event & 1000 & 25 & 532 & 1 & -22.8 & -24.2 & 38.7 & 0.40 & -40.7 & 2.22 & -44.3 & 10486 \\
\hline 7840 & CSPAD & Event & 2000 & 10 & 532 & 0.5 & -9.3 & -7.9 & 28.4 & 0.06 & -11.6 & 0.32 & -12.0 & 7277 \\
\hline 7825 & CSPAD & Event & 60 & 10 & 532 & 21 & -8.0 & -8.8 & 30.3 & 0.17 & -13.3 & 0.83 & -14.0 & 5739 \\
\hline 7821 & CSPAD & Event & 1000 & 20 & 532 & 1 & -24.9 & -23.1 & 37.1 & 0.43 & -40.2 & 2.08 & -42.1 & 5385 \\
\hline 7810 & CSPAD & Event & 110 & 60 & 532 & 10 & -19.0 & -17.2 & 29.1 & 0.08 & -22.3 & 0.43 & -23.0 & 3981 \\
\hline 7249 & CSPAD & Event & 1000 & 10 & 532 & 1.5 & -21.2 & -22.7 & 45.4 & -0.22 & -14.6 & -1.03 & -13.7 & 1901 \\
\hline 7827 & APD & Event & 1000 & 40 & 850 & 0.65 & -2.3 & -0.4 & 28.2 & -0.09 & 1.2 & -0.44 & 1.6 & 3929 \\
\hline 7090 & МCP & Interval & 10 & 150 & 532 & 100 & -23.4 & -22.1 & 29.8 & -0.14 & -17.4 & -0.64 & -17.3 & 16474 \\
\hline 8834 & MCP & Event & 20 & 50 & 532 & 100 & -35.7 & -34.3 & 27.7 & -0.06 & -33.8 & -0.23 & -34.0 & 7624 \\
\hline 7941 & MCP & Event & 10 & 50 & 532 & 100 & -34.4 & -29.1 & 30.4 & -0.09 & -31.4 & -0.39 & -31.4 & 4599 \\
\hline 7105 & MCP & Interval & 10 & 200 & 532 & 100 & -25.7 & -19.8 & 48.0 & -0.08 & -22.9 & -0.44 & -22.1 & 3486 \\
\hline 7110 & MCP & Interval & 10 & 150 & 532 & 100 & -21.7 & -13.3 & 35.0 & -0.26 & -11.8 & -1.17 & -11.7 & 1285 \\
\hline 7124 & MCP & Interval & 10 & 200 & 532 & 100 & -33.2 & -27.1 & 35.1 & 0.26 & -44.2 & 1.53 & -47.4 & 1193 \\
\hline 1879 & PMT & Event & 300 & 150 & 532 & 2.5 & -17.1 & -18.3 & 38.9 & 0.27 & -27.4 & 1.39 & -29.1 & 7182 \\
\hline 1868 & PMT & Event & 300 & 300 & 532 & 2.5 & 3.2 & 3.6 & 39.6 & -0.39 & 18.2 & -1.85 & 19.2 & 6221 \\
\hline 1887 & PMT & Event & 300 & 300 & 532 & 2.5 & -53.2 & -49.7 & 32.9 & 0.06 & -55.5 & 0.36 & -56.2 & 4300 \\
\hline 7407 & PMT & Event & 300 & 200 & 532 & 2.5 & -19.0 & -17.0 & 36.8 & -0.01 & -18.6 & 0.02 & -19.2 & 4236 \\
\hline 1886 & PMT & Event & 300 & 300 & 532 & 2.5 & 7.8 & 14.4 & 46.9 & -1.59 & 64.8 & -7.58 & 69.9 & 3492 \\
\hline 7841 & PMT & Event & 2000 & 10 & 532 & 0.4 & -22.8 & -22.4 & 27.1 & 0.17 & -27.7 & 0.80 & -28.3 & 2631 \\
\hline 1891 & PMT & Event & 300 & 250 & 532 & 2.5 & -22.1 & -16.6 & 36.2 & -0.22 & -16.0 & -0.94 & -15.9 & 1978 \\
\hline 1889 & PMT & Event & 300 & 300 & 532 & 2.5 & -1.4 & 1.6 & 37.4 & -0.24 & 6.3 & -1.12 & 6.8 & 1222 \\
\hline 7501 & PMT & Interval & 10 & 200 & 532 & 100 & -16.5 & -15.6 & 23.8 & 0.15 & -22.9 & 0.81 & -24.1 & 1052 \\
\hline 1874 & PMT & Event & 300 & 300 & 532 & 2.5 & -20.1 & -18.2 & 24.8 & -0.28 & -12.5 & -1.25 & -12.0 & 971 \\
\hline 1890 & PMT & Event & 300 & 300 & 532 & 2.5 & -18.9 & -12.3 & 40.4 & -0.29 & -12.4 & -1.32 & -11.8 & 708 \\
\hline
\end{tabular}


Table A2. SLR residual statistics of CODE's MGEX orbit in next periods since the beginning of CODE's MGEX orbits. Abbreviations used: First NP, date of first registered normal point; Last NP, date of last registered normal point; AVG, average (mm); STD, standard deviation (mm); Slope E, regression slope of SLR residuals as a function of elevation angle $\left(\mathrm{mm} /{ }^{\circ}\right)$; Obs. No., number of observations.

\begin{tabular}{|c|c|c|c|c|c|c|c|c|c|c|c|c|c|c|c|}
\hline \multirow[b]{2}{*}{ SVN } & \multirow[b]{2}{*}{ Type } & \multirow{2}{*}{$\begin{array}{c}\text { First NP } \\
\text { (DD-MM-YY) }\end{array}$} & \multirow{2}{*}{$\begin{array}{c}\text { Last NP } \\
\text { (DD-MM-YY) }\end{array}$} & \multicolumn{4}{|c|}{ 2012-2014 } & \multicolumn{4}{|c|}{ January 2015-July 2017} & \multicolumn{4}{|c|}{ August 2017-September 2017} \\
\hline & & & & $\begin{array}{l}\text { AVG } \\
(\mathrm{mm})\end{array}$ & $\begin{array}{l}\text { STD } \\
(\mathrm{mm})\end{array}$ & $\begin{array}{l}\text { Slope E } \\
\left(\mathrm{mm} /{ }^{\circ}\right)\end{array}$ & Obs. No. & $\begin{array}{l}\text { AVG } \\
(\mathrm{mm})\end{array}$ & $\begin{array}{l}\text { STD } \\
(\mathrm{mm})\end{array}$ & $\begin{array}{l}\text { Slope E } \\
\left(\mathrm{mm} /{ }^{\circ}\right)\end{array}$ & Obs.No. & $\begin{array}{l}\text { AVG } \\
(\mathrm{mm})\end{array}$ & $\begin{array}{l}\text { STD } \\
(\mathrm{mm})\end{array}$ & $\begin{array}{l}\text { Slope E } \\
\left(\mathrm{mm} /{ }^{\circ}\right)\end{array}$ & Obs. No. \\
\hline 35 & II & $25-05-12$ & 04-05-13 & -27 & 28 & -0.1 & 671 & - & - & - & - & - & - & - & - \\
\hline 36 & II & $24-05-12 \mid 28-09-15$ & 03-03-14 | 26-10-15 & -30 & 26 & -0.2 & 4030 & -36 & 33 & -0.5 & 139 & - & - & - & - \\
\hline 101 & IOV & 25-05-12 & active & -60 & 80 & -2.1 & 13411 & -44 & 35 & -0.5 & 12388 & -4 & 18 & -0.1 & 417 \\
\hline 102 & IOV & $24-05-12$ & active & -63 & 75 & -1.9 & 13863 & -44 & 31 & -0.2 & 11234 & -10 & 16 & 0.0 & 397 \\
\hline 103 & IOV & $03-12-12$ & active & -59 & 76 & -2.1 & 10202 & -46 & 38 & -0.5 & 12571 & -10 & 25 & -0.2 & 532 \\
\hline 104 & IOV & $15-12-12$ & 27-05-14 & -56 & 75 & -2.1 & 7701 & - & - & - & - & - & - & - & - \\
\hline 201 & $\mathrm{FOC}^{*}$ & $11-12-14$ & active & -50 & 53 & -1.6 & 29 & -28 & 31 & -0.1 & 9045 & 2 & 23 & 0.1 & 291 \\
\hline 202 & FOC $^{*}$ & $18-03-15$ & active & - & - & - & - & -28 & 32 & -0.2 & 6374 & -2 & 20 & 0.2 & 261 \\
\hline 203 & FOC & 27-05-15 & active & - & - & - & - & -38 & 38 & -0.6 & 5412 & 2 & 24 & -0.1 & 234 \\
\hline 204 & FOC & $24-05-15$ & active & - & - & - & - & -38 & 38 & -0.7 & 5562 & 6 & 17 & -0.2 & 280 \\
\hline 205 & FOC & 09-11-15 & active & - & - & - & - & -40 & 35 & -0.5 & 5202 & -13 & 33 & -0.6 & 326 \\
\hline 206 & FOC & $10-11-15$ & active & - & - & - & - & -41 & 36 & -0.5 & 4718 & -7 & 27 & -0.5 & 281 \\
\hline 207 & FOC & 23-03-17 & active & - & - & - & - & -38 & 39 & -0.9 & 824 & -1 & 26 & -0.2 & 268 \\
\hline 208 & FOC & $26-02-16$ & active & - & - & - & - & -42 & 37 & -0.7 & 5273 & -8 & 22 & -0.1 & 366 \\
\hline 209 & FOC & $25-02-16$ & active & - & - & - & - & -39 & 37 & -0.7 & 5202 & -1 & 22 & -0.3 & 388 \\
\hline 210 & FOC & 01-09-16 & active & - & - & - & - & -34 & 34 & -0.3 & 2437 & -7 & 26 & -0.4 & 305 \\
\hline 211 & FOC & $02-09-16$ & active & - & - & - & - & -34 & 35 & -0.3 & 2308 & -10 & 28 & -0.3 & 255 \\
\hline 212 & FOC & 01-05-17 & active & - & - & - & - & -36 & 26 & -0.4 & 952 & 3 & 22 & -0.3 & 371 \\
\hline 213 & FOC & 01-05-17 & active & - & - & - & - & -33 & 26 & -0.4 & 1094 & 2 & 21 & -0.3 & 466 \\
\hline 214 & FOC & $22-03-17$ & active & - & - & - & - & -38 & 35 & -0.5 & 948 & -2 & 30 & -0.4 & 291 \\
\hline 301 & GIOVE & 25-05-12 & $18-06-12$ & 136 & 67 & -2.1 & 129 & - & - & - & - & - & - & - & - \\
\hline 302 & GIOVE & $25-05-12$ & $23-07-12$ & 58 & 44 & 0.6 & 365 & - & - & - & - & - & - & - & - \\
\hline 408 & $\begin{array}{c}\text { BDS-2 } \\
\text { IGSO }\end{array}$ & $30-10-13$ & active & -39 & 57 & 0.7 & 1737 & -35 & 55 & 0.4 & 3582 & -30 & 21 & 0.3 & 95 \\
\hline 410 & $\begin{array}{l}\text { BDS-2 } \\
\text { IGSO }\end{array}$ & $27-10-13$ & active & -14 & 64 & 0.6 & 2686 & -14 & 58 & 0.9 & 3889 & -12 & 33 & 0.2 & 192 \\
\hline 412 & $\begin{array}{l}\text { BDS-2 } \\
\text { MEO }\end{array}$ & $28-10-13$ & active & -6 & 43 & -0.2 & 3534 & -10 & 38 & -0.1 & 6399 & -12 & 19 & 0.2 & 239 \\
\hline 417 & $\begin{array}{l}\text { BDS-2 } \\
\text { IGSO }\end{array}$ & $20-07-16$ & active & - & - & - & - & -20 & 55 & 1.2 & 1526 & -44 & 54 & 1.8 & 72 \\
\hline 501 & QZS-1 & 01-01-14 & active & -46 & 128 & 4.0 & 1056 & -96 & 77 & 1.6 & 3039 & -29 & 101 & 1.1 & 154 \\
\hline 712 & $\mathrm{M}$ & $21-10-12$ & $18-12-12$ & 12 & 47 & 0.0 & 77 & - & - & - & - & - & - & - & - \\
\hline 714 & $\mathrm{M}$ & 08-03-14 & $12-10-15$ & 43 & 32 & 2.0 & 30 & -15 & 83 & 2.3 & 253 & - & - & - & - \\
\hline 715 & M & 25-05-12 & 03-07-17 & -12 & 43 & 0.8 & 2847 & -10 & 39 & 0.3 & 2587 & - & - & - & - \\
\hline 716 & M & $25-05-12$ & active & -3 & 43 & 0.7 & 5823 & -6 & 26 & 0.2 & 2945 & -5 & 30 & -0.5 & 145 \\
\hline 717 & M & $25-05-12$ & active & -3 & 44 & 1.0 & 3627 & -5 & 31 & 0.6 & 2841 & 15 & 17 & 0.4 & 116 \\
\hline 719 & $\mathrm{M}$ & $25-05-12$ & active & -7 & 32 & 0.4 & 2628 & -18 & 33 & -0.1 & 2287 & 1 & 24 & -0.4 & 41 \\
\hline 720 & $\mathrm{M}$ & $24-05-12$ & active & -8 & 30 & 0.5 & 2787 & -21 & 31 & -0.6 & 2431 & 8 & 27 & -1.2 & 39 \\
\hline
\end{tabular}


Table A2. Cont.

\begin{tabular}{|c|c|c|c|c|c|c|c|c|c|c|c|c|c|c|c|}
\hline \multirow[b]{2}{*}{ SVN } & \multirow[b]{2}{*}{ Type } & \multirow{2}{*}{$\begin{array}{c}\text { First NP } \\
\text { (DD-MM-YY) }\end{array}$} & \multirow{2}{*}{$\begin{array}{c}\text { Last NP } \\
\text { (DD-MM-YY) }\end{array}$} & \multicolumn{4}{|c|}{ 2012-2014 } & \multicolumn{4}{|c|}{ January 2015-July 2017} & \multicolumn{4}{|c|}{ August 2017-September 2017} \\
\hline & & & & $\begin{array}{l}\text { AVG } \\
(\mathrm{mm})\end{array}$ & $\begin{array}{l}\text { STD } \\
(\mathrm{mm})\end{array}$ & $\begin{array}{l}\begin{array}{l}\text { Slope E } \\
\left(\mathrm{mm} /{ }^{\circ}\right)\end{array} \\
\end{array}$ & Obs. No. & $\begin{array}{l}\text { AVG } \\
(\mathrm{mm})\end{array}$ & $\begin{array}{l}\text { STD } \\
(\mathrm{mm})\end{array}$ & $\begin{array}{l}\begin{array}{l}\text { Slope E } \\
\left(\mathrm{mm} /{ }^{\circ}\right)\end{array} \\
\end{array}$ & Obs.No. & $\begin{array}{l}\text { AVG } \\
(\mathrm{mm})\end{array}$ & $\begin{array}{l}\text { STD } \\
(\mathrm{mm})\end{array}$ & $\begin{array}{l}\begin{array}{l}\text { Slope E } \\
\left(\mathrm{mm} /{ }^{\circ}\right)\end{array} \\
\end{array}$ & Obs. No. \\
\hline 721 & $\mathrm{M}$ & $25-05-12$ & active & -12 & 33 & 0.4 & 3186 & -27 & 32 & -0.2 & 2829 & -2 & 23 & 0.2 & 165 \\
\hline 723 & $\mathrm{M}$ & $25-05-12$ & 02-03-16 & -27 & 44 & -0.4 & 6589 & -63 & 81 & -2.1 & 1396 & - & - & - & - \\
\hline 724 & $\mathrm{M}$ & $24-05-12$ & $11-02-14$ & -10 & 41 & 0.5 & 3170 & - & - & - & - & - & - & - & - \\
\hline 725 & $\mathrm{M}$ & $26-05-12$ & $31-07-14$ & -16 & 38 & -0.7 & 2384 & - & - & - & - & - & - & - & - \\
\hline 728 & $\mathrm{M}$ & $25-05-12$ & $25-06-13$ & -39 & 29 & 0.2 & 1298 & - & - & - & - & - & - & - & - \\
\hline 729 & $\mathrm{M}$ & $25-05-12$ & $11-09-12$ & -35 & 32 & 0.7 & 2109 & - & - & - & - & - & - & - & - \\
\hline 730 & $\mathrm{M}$ & $25-05-12$ & active & -16 & 33 & 0.1 & 3366 & -27 & 38 & -0.9 & 2425 & -35 & 42 & -1.2 & 142 \\
\hline 731 & M & $25-05-12$ & active & -14 & 29 & 0.3 & 6081 & -27 & 32 & -0.5 & 6485 & -2 & 19 & -0.5 & 73 \\
\hline 732 & M & $25-05-12$ & active & -13 & 30 & 0.6 & 6631 & 10 & 40 & 1.0 & 6433 & -28 & 36 & 1.3 & 68 \\
\hline 733 & $\mathrm{M}$ & $25-05-12$ & active & -6 & 33 & 0.6 & 2852 & -2 & 30 & 0.2 & 2207 & 34 & 31 & 1.0 & 120 \\
\hline 734 & M & $25-05-12$ & active & -3 & 38 & 0.4 & 5238 & -7 & 31 & -0.2 & 2667 & -7 & 21 & -0.1 & 104 \\
\hline 735 & $\mathrm{M}$ & $25-05-12$ & active & -6 & 31 & 0.5 & 6555 & -2 & 37 & 0.5 & 7297 & 2 & 32 & 1.0 & 114 \\
\hline 736 & M & $25-05-12$ & active & -6 & 52 & 1.1 & 10894 & 2 & 46 & 0.8 & 9286 & 0 & 27 & 0.3 & 450 \\
\hline 737 & M & $25-05-12$ & $21-11-16$ & -21 & 36 & 0.3 & 11603 & -41 & 81 & -1.8 & 11614 & - & - & - & - \\
\hline 738 & $\mathrm{M}$ & $25-05-12$ & $13-02-16$ & -11 & 38 & 0.7 & 11024 & -13 & 32 & 0.4 & 6222 & - & - & - & - \\
\hline 742 & $\mathrm{M}$ & $24-05-12$ & active & -12 & 31 & 0.5 & 10610 & -12 & 26 & -0.3 & 12500 & -9 & 28 & -0.1 & 600 \\
\hline 743 & $\mathrm{M}$ & 23-09-12 & active & -13 & 29 & 0.3 & 7566 & -18 & 29 & -0.4 & 11436 & -15 & 24 & -0.3 & 542 \\
\hline 744 & $\mathrm{M}$ & $24-05-12$ & active & -13 & 33 & 0.7 & 10764 & -19 & 27 & -0.2 & 18971 & -20 & 27 & -0.4 & 1149 \\
\hline 745 & M & $25-05-12$ & active & -16 & 30 & 0.4 & 21515 & -22 & 29 & -0.5 & 19863 & -18 & 29 & -0.6 & 869 \\
\hline 746 & $\mathrm{M}$ & $25-05-12$ & $11-04-15$ & -18 & 33 & 0.5 & 20123 & -19 & 33 & -0.5 & 2288 & - & - & - & - \\
\hline 747 & M & $05-07-13$ & active & -12 & 32 & 0.5 & 6379 & -20 & 25 & -0.1 & 18677 & -21 & 27 & -0.3 & 1391 \\
\hline 801 & K1 & 09-01-13 & $22-02-13$ & -2 & 36 & 0.3 & 117 & - & - & - & - & - & - & - & - \\
\hline 802 & K1 & $28-01-16$ & active & - & - & - & - & -11 & 23 & 0.0 & 10708 & -3 & 50 & 0.1 & 1054 \\
\hline 851 & M & $28-02-16$ & active & - & - & - & - & -22 & 28 & -0.3 & 5750 & -2 & 18 & -0.3 & 359 \\
\hline 853 & $\mathrm{M}$ & $28-06-16$ & active & - & - & - & - & -29 & 24 & 0.5 & 6841 & -18 & 26 & 0.2 & 1242 \\
\hline 854 & $\mathrm{M}$ & $16-04-14$ & active & -17 & 30 & 0.4 & 3281 & -21 & 24 & 0.1 & 15107 & -9 & 22 & 0.5 & 353 \\
\hline 855 & M+ & $06-08-14$ & active & 21 & 29 & 0.3 & 1448 & 14 & 26 & -0.2 & 17513 & 30 & 17 & -0.2 & 659 \\
\hline
\end{tabular}


Table A3. Sample information about the satellites; possible to get from GOVUS database. Abbreviations used: MW offset, microwave antenna offset (m); SLR offset, laser retroreflector array offset $(\mathrm{m})$; Alt., altitude $(\mathrm{km})$; Rev., revolution period $(\mathrm{h})$; i, inclination $\left({ }^{\circ}\right)$; e, eccentricity.

\begin{tabular}{|c|c|c|c|c|c|c|c|c|c|c|c|c|c|c|c|c|c|}
\hline \multirow[b]{2}{*}{ PRN } & \multirow[b]{2}{*}{ SVN } & \multirow[b]{2}{*}{ Norad } & \multirow[b]{2}{*}{ Cospar } & \multicolumn{2}{|c|}{ Date } & \multicolumn{2}{|c|}{ Offset } & \multirow{2}{*}{$\begin{array}{l}\text { Satellite } \\
\text { Type }\end{array}$} & \multirow{2}{*}{$\begin{array}{l}\text { Mass } \\
\text { (kg) }\end{array}$} & \multicolumn{5}{|c|}{ Orbit } & \multirow{2}{*}{$\begin{array}{l}\text { LRA Size } \\
\quad(\mathrm{mm})\end{array}$} & \multirow[b]{2}{*}{ Plane } & \multirow[b]{2}{*}{ Slo } \\
\hline & & & & $\begin{array}{c}\text { From } \\
\text { (DD-MM-YY) }\end{array}$ & $\begin{array}{c}\text { To } \\
\text { (DD-MM-YY) }\end{array}$ & MW (m) & SLR (m) & & & Alt. (km) & Rev. (h) & $\mathrm{i}\left({ }^{\circ}\right)$ & e & Type & & & \\
\hline $\mathrm{C} 13$ & 417 & 41434 & 2016-021A & $12-10-16$ & active & $\begin{array}{l}0.6000 \\
0.0000 \\
1.1000 \\
0.6000\end{array}$ & $\begin{array}{c}-0.4026 \\
-0.5730 \\
1.0934 \\
-0.4321\end{array}$ & IGSO & 1900 & 35,790 & 23.93 & 53.31 & 0.0025 & IGSO & $316 / 280$ & C-95E & 1 \\
\hline $\mathrm{C} 14$ & 415 & 38775 & 2012-050B & $18-09-12$ & active & $\begin{array}{l}0.0000 \\
1.1000 \\
0.1600\end{array}$ & $\begin{array}{c}-0.5621 \\
1.1128 \\
1.0146\end{array}$ & MEO & 1900 & 21,529 & 12.88 & 56.21 & 0.0023 & MEO & $316 / 280$ & C-B & 4 \\
\hline E14 & 202 & 40129 & 2014-050B & $22-08-14$ & active & $\begin{array}{c}-0.0100 \\
1.0500 \\
0.0000\end{array}$ & $\begin{array}{l}0.0149 \\
0.5581 \\
0.8280\end{array}$ & FOC & 662 & 23,225 & 12.94 & 50.1 & 0.002 & MEO & $331.0 / 248.7$ & E-Ext & 2 \\
\hline E01 & 301 & 28922 & 2005-051A & 28-12-05 & $30-06-12$ & $\begin{array}{l}0.0000 \\
0.8800\end{array}$ & $\begin{array}{l}0.6550 \\
0.6880\end{array}$ & GIOVE-A & 550 & 23,225 & 14.08 & 56.042 & 0.0008 & MEO & $308 / 408$ & E-GIOVEA & A 1 \\
\hline R17 & 802 & 40315 & 2014-075A & 27-01-16 & $15-12-16$ & $\begin{array}{c}0.0000 \\
0.0000 \\
2.0830 \\
-0.5450\end{array}$ & $\begin{array}{l}0.0000 \\
0.0000 \\
1.4700 \\
0.1370\end{array}$ & K1 & 750 & 19,132 & 11.26 & 64.8 & 0.0015 & MEO & $\begin{array}{c}\mathrm{R}=316.8 / \\
\mathrm{r}=171.2\end{array}$ & R-II & 1 \\
\hline $\mathrm{R} 21$ & 855 & 40001 & 2014-032A & 02-08-14 & active & $\begin{array}{l}0.0000 \\
2.3989 \\
0.0109\end{array}$ & $\begin{array}{l}-0.0030 \\
1.8735\end{array}$ & $\mathrm{M}+$ & 1415 & 19,132 & 11.26 & 64.8 & 0.0015 & MEO & $311.0 / 510.8$ & R-III & 5 \\
\hline G29 & 57 & 32384 & $2007-062 \mathrm{~A}$ & $20-12-07$ & active & $\begin{array}{c}-0.0045 \\
0.7918 \\
-0.1700\end{array}$ & $\begin{array}{c}- \\
-1.0927\end{array}$ & IIR-M & 1100 & 20,200 & 11.9667 & 55 & 0.02 & MEO & None & G-C & 1 \\
\hline E20 & 104 & 38858 & 2012-055B & $12-10-12$ & active & $\begin{array}{c}0.0300 \\
0.9500 \\
-0.0009\end{array}$ & $\begin{array}{l}0.0340 \\
0.6225 \\
1.1491\end{array}$ & IOV & 696 & 23,225 & 14.08 & 56 & 0.002 & MEO & $430 / 470$ & $\mathrm{E}-\mathrm{C}$ & 5 \\
\hline J01 & 501 & 37158 & 2010-045A & $11-09-10$ & active & $\begin{array}{c}-0.0009 \\
0.0029 \\
3.0000\end{array}$ & $\begin{array}{l}1.1491 \\
0.5529 \\
2.6854\end{array}$ & QZS-1 & 1800 & 36,000 & 23.93 & 40.74 & 0.074 & $\begin{array}{c}\text { QZS } \\
\text { (IGSO) }\end{array}$ & $400 / 400$ & $\mathrm{~J}-1$ & 1 \\
\hline
\end{tabular}




\section{References}

1. Montenbruck, O.; Steigenberger, P.; Prange, L.; Deng, Z.; Zhao, Q.; Perosanz, F.; Romero, I.; Noll, C.; Stürze, A.; Weber, G.; et al. The Multi-GNSS Experiment (MGEX) of the International GNSS Service (IGS)-Achievements, prospects and challenges. Adv. Space Res. 2017, 59, 1671-1697. [CrossRef]

2. Beutler, G.; Rothacher, M.; Schaer, S.; Springer, T.A.; Kouba, J.; Neilan, R.E. The International GPS Service (IGS): An interdisciplinary service in support of Earth sciences. Adv. Space Res. 1999, 23, 631-653. [CrossRef]

3. Combrinck, L. Satellite Laser Ranging. In Sciences of Geodesy—I; Xu, G., Ed.; Springer: Berlin/Heidelberg, Germany, 2010; pp. 301-338, ISBN 978-3-642-11740-4.

4. Loyer, S.; Perosanz, F.; Mercier, F.; Capdeville, H.; Mezerette, A. CNES/CLS CNES/CLS IGS Analysis Analysis Center: Contribution Center: Contribution to MGEX and to MGEX and Recent Activities. In Proceedings of the 2016 IGS Workshop, Sydney, Australia, 8-12 February 2016.

5. Prange, L.; Orliac, E.; Dach, R.; Arnold, D.; Beutler, G.; Schaer, S.; Jäggi, A. CODE's five-system orbit and clock solution-The challenges of multi-GNSS data analysis. J. Geod. 2017, 91, 345-360. [CrossRef]

6. Uhlemann, M.; Gendt, G.; Ramatschi, M.; Deng, Z. GFZ Global Multi-GNSS Network and Data Processing Results. In IAG 150 Years; Rizos, C., Willis, P., Eds.; Springer International Publishing: Cham, Switzerland, 2015; Volume 143, pp. 673-679, ISBN 978-3-319-24603-1.

7. Pearlman, M.R.; Degnan, J.J.; Bosworth, J.M. The International Laser Ranging Service. Adv. Space Res. 2002, 30, 135-143. [CrossRef]

8. Seeber, G. Satellite Geodesy: Foundations, Methods, and Applications; Walter de Gruyter: Berlin, Germany, 2008; ISBN 978-3-11-020008-9.

9. Appleby, G.; Rodríguez, J.; Altamimi, Z. Assessment of the accuracy of global geodetic satellite laser ranging observations and estimated impact on ITRF scale: Estimation of systematic errors in LAGEOS observations 1993-2014. J. Geodesy 2016, 90, 1371-1388. [CrossRef]

10. Artyukh, Y.; Bespalko, V.; Boole, E.; Vedin, V. Advances of High-precision Riga Event Timers. In Proceedings of the 16th International Workshop on Laser Ranging, Poznan, Poland, 12-17 October 2008.

11. Mendes, V.B. High-accuracy zenith delay prediction at optical wavelengths. Geophys. Res. Lett. $2004,31$. [CrossRef]

12. Hulley, G.C.; Pavlis, E.C. A ray-tracing technique for improving Satellite Laser Ranging atmospheric delay corrections, including the effects of horizontal refractivity gradients. J. Geophys. Res. 2007, 112. [CrossRef]

13. Altamimi, Z.; Rebischung, P.; Métivier, L.; Collilieux, X. ITRF2014: A new release of the International Terrestrial Reference Frame modeling nonlinear station motions: ITRF2014. J. Geophys. Res. Solid Earth 2016, 121, 6109-6131. [CrossRef]

14. Seitz, M.; Bloßfeld, M.; Angermann, D.; Schmid, R.; Gerstl, M.; Seitz, F. The new DGFI-TUM realization of the ITRS: DTRF2014 (Data). PANGAEA 2016. [CrossRef]

15. Blossfeld, M. The Key Role of Satellite Laser Ranging Towards the Integrated Estimation of Geometry, Rotation and Gravitational Field of the Earth. Ph.D. Thesis, Technische Universität München, München, Germany, 2015.

16. Sośnica, K.; Jäggi, A.; Thaller, D.; Dach, R.; Meyer, U. Earth Rotation and Gravity Field Parameters from Satellite Laser Ranging. In Proceedings of the 19th International Workshop on Laser Ranging, Celebrating 50 Year of SLR: Remembering the Past and Planning for the Future, Annapolis, MD, USA, 27-31 October 2014.

17. Sośnica, K. Determination of Precise Satellite Orbits and Geodetic Parameters using Satellite Laser Ranging; Astronomical Institute, University of Bern: Bern, Switzerland, 2014; ISBN 978-83-938898-0-8.

18. Miller, J.; LaBrecque, J.; Oria, A.J. Expert Advice: Laser Reflectors to Ride on Board GPS III; GPS World: Cleveland, $\mathrm{OH}, \mathrm{USA}, 2013$.

19. Hugentobler, U. Ranging the GNSS Constellation. In Proceedings of the 20th International Workshop on Laser Ranging, Potsdam, Germany, 10-14 October 2016.

20. Urschl, C.; Beutler, G.; Gurtner, W.; Hugentobler, U.; Schaer, S. Contribution of SLR tracking data to GNSS orbit determination. Adv. Space Res. 2007, 39, 1515-1523. [CrossRef]

21. Hackel, S.; Steigenberger, P.; Hugentobler, U.; Uhlemann, M.; Montenbruck, O. Galileo orbit determination using combined GNSS and SLR observations. GPS Solut. 2015, 19, 15-25. [CrossRef]

22. Pavlis, E.C. Comparison of GPS S/C orbits determined from GPS and SLR tracking data. Adv. Space Res. 1995, 16, 55-58. [CrossRef] 
23. Bury, G.; Sośnica, K.; Zajdel, R. Multi-GNSS orbit determination using Satellite Laser Ranging. J. Geod. 2017. [under review].

24. Springer, T.A.; Beutler, G.; Rothacher, M. A New Solar Radiation Pressure Model for GPS Satellites. GPS Solut. 1999, 2, 50-62. [CrossRef]

25. Arnold, D.; Meindl, M.; Beutler, G.; Dach, R.; Schaer, S.; Lutz, S.; Prange, L.; Sośnica, K.; Mervart, L.; Jäggi, A. CODE's new solar radiation pressure model for GNSS orbit determination. J. Geod. 2015, 89, 775-791. [CrossRef]

26. Montenbruck, O.; Steigenberger, P.; Hugentobler, U. Enhanced solar radiation pressure modeling for Galileo satellites. J. Geod. 2015, 89, 283-297. [CrossRef]

27. Steigenberger, P.; Montenbruck, O.; Hugentobler, U. GIOVE-B solar radiation pressure modeling for precise orbit determination. Adv. Space Res. 2015, 55, 1422-1431. [CrossRef]

28. Guo, J.; Chen, G.; Zhao, Q.; Liu, J.; Liu, X. Comparison of solar radiation pressure models for BDS IGSO and MEO satellites with emphasis on improving orbit quality. GPS Solut. 2017, 21, 511-522. [CrossRef]

29. Bruni, S.; Rebischung, P.; Zerbini, S.; Altamimi, Z.; Errico, M.; Santi, E. Assessment of the possible contribution of space ties on-board GNSS satellites to the terrestrial reference frame. J. Geod. 2017. [CrossRef]

30. Thaller, D.; Dach, R.; Seitz, M.; Beutler, G.; Mareyen, M.; Richter, B. Combination of GNSS and SLR observations using satellite co-locations. J. Geod. 2011, 85, 257-272. [CrossRef]

31. Fridelance, P.; Samain, E.; Fridelance, P. T2L2-Time transfer by Laser link: A new optical time transfer generation. Exp. Astron. 1997, 7, 191-207. [CrossRef]

32. Exertier, P.; Samain, E.; Courde, C.; Aimar, M.; Torre, J.M.; Rovera, G.D.; Abgrall, M.; Uhrich, P.; Sherwood, R.; Herold, G.; et al. Sub-ns time transfer consistency: A direct comparison between GPS CV and T2L2. Metrologia 2016, 53, 1395. [CrossRef]

33. Otsubo, T.; Appleby, G.M.; Gibbs, P. Glonass Laser Ranging Accuracy With Satellite Signature Effect. Surv. Geophys. 2001, 22, 509-516. [CrossRef]

34. Pavlis, E.; LaBrecque, J.; Ries, J.; Gross, R. Impact of SLR tracking of GNSS Constellations on Science. In Proceedings of the 16th International Workshop on Laser Ranging, Metsovo, Greece, 14-19 September 2009.

35. Petit, G.; Luzum, B. IERS Conventions (2010); IERS Technical Note, 36; Verlag des Bundesamts fur Kartographie und Geodasie: Frankfurt am Main, Germany, 2011.

36. Wilkinson, M. Tracking Many GNSS: Introduction. In Proceedings of the 18th International Workshop on Laser Ranging, Fujiyoshida, Japan, 11-15 November 2013.

37. IGS MGEX Analysis. Available online: http://mgex.igs.org/analysis/slrres.php (accessed on 12 October 2017).

38. Sośnica, K.; Thaller, D.; Dach, R.; Steigenberger, P.; Beutler, G.; Arnold, D.; Jäggi, A. Satellite laser ranging to GPS and GLONASS. J. Geod. 2015, 89, 725-743. [CrossRef]

39. Dach, R.; Lutz, S.; Walser, P.; Fridez, P. Bernese GNSS Software Version 5.2. User Manual; Astronomical Institute, Faculty of Science, University of Bern: Bern, Switzerland, 2015.

40. Guo, J.; Xu, X.; Zhao, Q.; Liu, J. Precise orbit determination for quad-constellation satellites at Wuhan University: Strategy, result validation, and comparison. J. Geod. 2016, 90, 143-159. [CrossRef]

41. JAXA QZSS Final Products webpage. Available online: http:/ / qz-vision.jaxa.jp/USE/en/finalp (accessed on 31 August 2017).

42. Noll, C.E. The crustal dynamics data information system: A resource to support scientific analysis using space geodesy. Adv. Space Res. 2010, 45, 1421-1440. [CrossRef]

43. Lyard, F.; Lefevre, F.; Letellier, T.; Francis, O. Modelling the global ocean tides: Modern insights from FES2004. Ocean Dyn. 2006, 56, 394-415. [CrossRef]

44. Montenbruck, O.; Schmid, R.; Mercier, F.; Steigenberger, P.; Noll, C.; Fatkulin, R.; Kogure, S.; Ganeshan, A.S. GNSS satellite geometry and attitude models. Adv. Space Res. 2015, 56, 1015-1029. [CrossRef]

45. Villiger, A.; Dach, R. International GNSS Service Technical Report 2016 (IGS Annual Report); IGS Central Bureau: Pasadena, CA, USA; University of Bern (Bern Open Publishing): Bern, Switzerland, 2017. [CrossRef]

46. ILRS Map of Stations. Available online: https://ilrs.cddis.eosdis.nasa.gov/network/stations/index.html (accessed on 12 October 2017).

47. EUROLAS Data Center (EDC) Stations. Available online: http://edc.dgfi.tum.de/en/stations (accessed on 12 October 2017). 
48. Dach, R.; Susnik, A.; Grahsl, A.; Villiger, A.; Arnold, D.; Prange, L.; Schaer, S.; Jaggi, A. GLONASS Satellite Orbit Modelling. In Proceedings of the IGS Workshop, Paris, France, 3-7 July 2017.

49. Guo, F.; Li, X.; Zhang, X.; Wang, J. Assessment of precise orbit and clock products for Galileo, BeiDou, and QZSS from IGS Multi-GNSS Experiment (MGEX). GPS Solut. 2017, 21, 279-290. [CrossRef]

50. Sośnica, K.; Prange, L.; Kaźmierski, K.; Bury, G.; Drożdżewski, M.; Zajdel, R.; Hadas, T. Validation of Galileo orbits using SLR with a focus on satellites launched into incorrect orbital planes. J. Geod. 2017. [CrossRef]

51. Chen, M.; Liu, Y.; Guo, J.; Song, W.; Zhang, P.; Wu, J.; Zhang, D. Precise Orbit Determination of BeiDou Satellites with Contributions from Chinese National Continuous Operating Reference Stations. Remote Sens. 2017, 9, 810. [CrossRef]

52. Zhao, Q.; Guo, J.; Li, M.; Qu, L.; Hu, Z.; Shi, C.; Liu, J. Initial results of precise orbit and clock determination for COMPASS navigation satellite system. J. Geod. 2013, 87, 475-486. [CrossRef]

53. Lou, Y.; Liu, Y.; Shi, C.; Yao, X.; Zheng, F. Precise orbit determination of BeiDou constellation based on BETS and MGEX network. Sci. Rep. 2015, 4. [CrossRef] [PubMed]

54. Steigenberger, P. Accuracy of Current and Future Satellite Navigation Systems; Habilitation, Technische Universität München: München, Germany, 2017.

55. Montenbruck, O.; Steigenberger, P.; Darugna, F. Semi-analytical solar radiation pressure modeling for QZS-1 orbit-normal and yaw-steering attitude. Adv. Space Res. 2017, 59, 2088-2100. [CrossRef]

56. Thaller, D.; Sośnica, K.; Dach, R.; Jäggi, A.; Beutler, G.; Mareyen, M.; Richter, B. Geocenter Coordinates from GNSS and Combined GNSS-SLR Solutions Using Satellite Co-locations. In Earth on the Edge: Science for a Sustainable Planet; Rizos, C., Willis, P., Eds.; Springer: Berlin/Heidelberg, Germany, 2014; Volume 139, pp. 129-134, ISBN 978-3-642-37221-6.

57. Fritsche, M.; Sośnica, K.; Rodríguez-Solano, C.J.; Steigenberger, P.; Wang, K.; Dietrich, R.; Dach, R.; Hugentobler, U.; Rothacher, M. Homogeneous reprocessing of GPS, GLONASS and SLR observations. J. Geod. 2014, 88, 625-642. [CrossRef]

58. ILRS Ground Segment description. Available online: https://ilrs.cddis.eosdis.nasa.gov/technology/ groundSegment/ (accessed on 12 October 2017).

59. Sośnica, K.; Bury, G.; Zajdel, R.; Kaźmierski, K.; Drożdżewski, M. Determination of SLR Station Coordinates on the Basis of Tracking 45 GNSS Satellites: Benefits for Future ITRF Realizations. In Proceedings of the EGU General Assembly Conference Abstracts, Vienna, Austria, 23-28 April 2017; Volume 19, p. 4437.

60. Global Geodetic Observing System; Plag, H.-P.; Pearlman, M., Eds.; Springer: Berlin/Heidelberg, Germany, 2009; ISBN 978-3-642-02686-7.

61. Delva, P.; Hees, A.; Bertone, S.; Richard, E.; Wolf, P. Test of the Gravitational Redshift with Stable Clocks in Eccentric Orbits: Application to Galileo Satellites 5 and 6. Class. Quantum Gravity 2015, 32, 232003. [CrossRef]

62. IGG Satellite Laser Ranging GNSS Satellites. Available online: http://geo2.igig.up.wroc.pl/wordpress/ gnss-satellites / (accessed on 12 October 2017).

63. Multi-GNSS Orbit Validation Visualizer Using GNSS. Available online: http:/ / www.govus.pl (accessed on 12 October 2017).

(C) 2017 by the authors. Licensee MDPI, Basel, Switzerland. This article is an open access article distributed under the terms and conditions of the Creative Commons Attribution (CC BY) license (http:/ / creativecommons.org/licenses/by/4.0/). 